\title{
New Developments in Solid Electrolytes for Thin-Film Lithium Batteries
}

\author{
Inseok Seo and Steve W. Martin \\ Department of Materials Science and Engineering, \\ Iowa State University, Iowa,
}

USA

\section{Introduction}

Research on lithium-ion secondary batteries began in the 1980s because of the growing demand for power sources for portable electronic devices. After the early 1990s, the demands for higher capacities and even smaller sizes energy systems significantly increased. Further, the explosive growth in the use of limited fossil fuels and their associated environmental issues and economical aspects are major concerns. Hence, the enormous growth in the demand for low-cost, environmentally friendly energy sources over the past decade has generated a significant need for high energy density portable energy sources.

The enormous growth in portable consumer electronic devices such as mobile phones, laptop computers, digital cameras, and personal digital assistants over the past decade has generated a large interest in compact, high-energy density and lightweight batteries. As power requirements become more demanding, batteries are also expected to provide higher energy densities. In recent decades, $\mathrm{LiCoO}_{2}$ and $\mathrm{LiMn}_{2} \mathrm{O}_{4}$ cathode materials and graphite anodes have been developed and are common in most lithium batteries(Kenji et al.; Peled et al., 1996; Peng et al., 1998; Wang et al., 2002; Xu et al., 2002). However, graphite-based materials are less attractive in terms of capacity when compared to lithium metal, $372 \mathrm{vs.}$ $3800 \mathrm{mAh} / \mathrm{g}$, respectively, in spite of graphite's higher cyclability and safer operation than lithium metal anodes (Tarascon and Armand, 2001). Even still, lithium-based batteries have become enormously important batteries due to their relatively high capacity and low weight. A comparison of many different anode (bottom) and cathode (top) combinations are shown in Figure (1)(Tarascon and Armand, 2001). Further, lithium is very lightweight and has a high electrochemical equivalency and these properties make lithium an attractive battery anode. Therefore, rechargeable lithium batteries are attractive for numerous reasons: high voltages, high energy densities, wide operating temperature ranges, good power density, flat discharge characteristics, and excellent shelf life. However, as shown in Figure (1) the 10-fold increase in capacity of Li metal over graphite has prompted continued effort to develop rechargeable lithium batteries based upon lithium metal anodes for use in a wide variety of applications.

Although the implementation of lithium metal as the anode material in lithium batteries is attractive, electrolytes with high ionic conductivity that are stable in contact with metallic 
lithium are still lacking. Around ten years ago, lithium batteries with lithium metal anodes using liquid electrolytes, which show the highest ionic conductivities, failed because of serious safety issues(Crowther and West, 2008). Lithium metal anodes tend to form dendrites during charging and discharging processes due to plating-out reactions between lithium metal and liquid electrolytes(Crowther and West, 2008). For these reasons, lithium-based solid-state electrolytes instead of liquid electrolytes are now of great interest and many researchers have been examining them in solid-state batteries because solid electrolytes do not have the aforementioned safety issues and show a smaller temperature dependence to the ionic conductivity compared to some liquid electrolytes. In addition, with the recent surge in interest of various kinds of portable electronic devices and electric and hybrid-electric vehicles, the importance of portable energy sources like secondary batteries has increased. It is widely recognized that allsolid-state energy devices show promise towards improving the safety and reliability of lithium batteries(Hayashi et al., 2009).

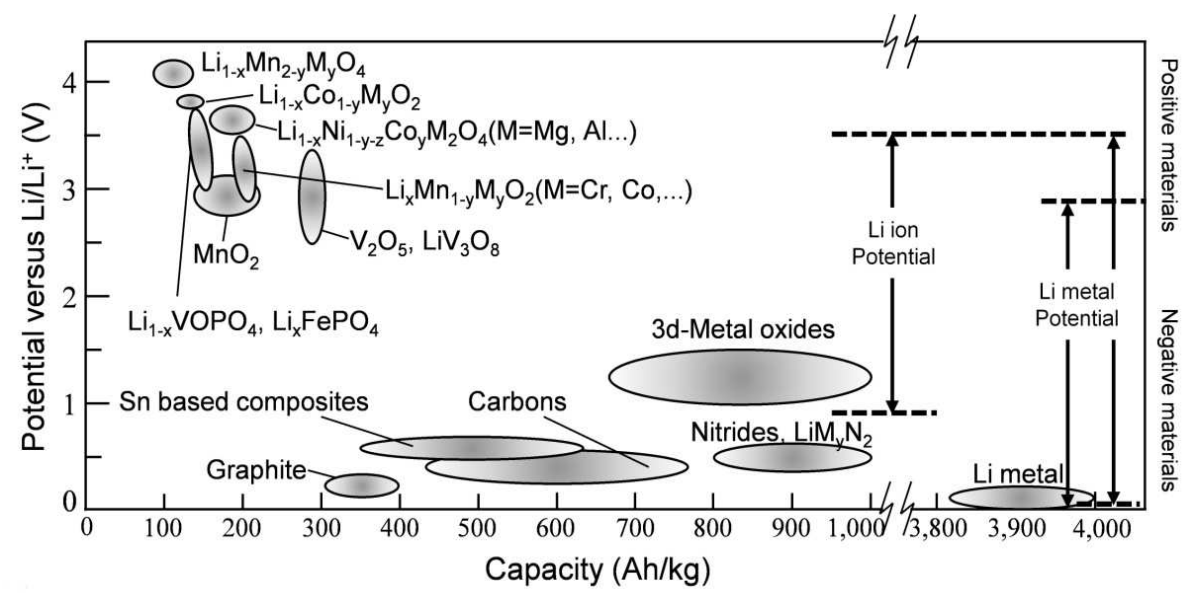

Fig. 1. Voltage versus capacity for positive- and negative- electrode materials presently used or under serious consideration for the next generation of rechargeable Li-based cells adopted from (Tarascon and Armand, 2001).

There is an additional interest in specialized lithium batteries for use in the semiconductor industry and for printed circuit-board applications. These types of batteries are of interest for applications such as non-volatile computer memory chips, smart cards, integrated circuits, and some medical applications(Albano et al., 2008; Souquet and Duclot, 2002). In addition, as the increasing tendency of many advanced technologies is towards miniaturization, the future development of batteries is aiming at smaller dimensions with higher power densities. The development of new technologies and miniaturization in the microelectronics industry has reduced the power and current requirements of small power electronic devices such as smart cards and other CMOS circuit applications(Albano et al., 2008; Souquet and Duclot, 2002). Therefore, developing improved solid-state thinfilm batteries will allow better compatibility with microelectronic processing and components. 
Therefore, solid-state lithium secondary batteries have attracted much attention because the replacement of conventional liquid electrolytes with an inorganic solid electrolyte may improve the safety and reliability of lithium batteries utilizing high capacity lithium metal anodes(Jones and Akridge, 1992).

Although solid-state batteries have many potential advantages over competitive batteries, solid electrolytes must have higher $\mathrm{Li}^{+}$ionic conductivity for them to succeed in commercial applications. Solid electrolytes are a key material of all-solid-state energy storage devices and have been extensively studied in the fields of materials science(Scholz and Meyer, 1994), polymer science(Croce et al., 2001; Fauteux et al., 1995; Song et al., 1999), and electrochemistry(Scholz and Meyer, 1994). Much research has been devoted to the preparation of solid electrolytes made of various materials including ceramics(Abe et al., 2005; Jak et al., 1999a; Jak et al., 1999b), glasses(Iriyama et al., 2005; Lee et al., 2002; Lee et al., 2007; Takada et al., 1995) and glass ceramics(Hayashi et al., 2010; Minami et al., 2011; Ohtomo et al., 2005).

Among these materials for electrolytes, amorphous or glassy materials often have superior ionic conductivities over corresponding crystalline materials because they can form over a wide range of compositions, have isotropic properties, do not have grain boundaries, and can form thin-films easily(Angell, 1983; Martin, 1991). Because of their more open disordered structure, amorphous materials typically have higher ionic conductivities than the corresponding crystalline material(Angell, 1983; Martin, 1991). In addition, single ion conduction can be realized because glassy materials belong to decoupled systems in which the mode of ion conduction relaxation is decoupled from the mode of structural relaxation(Kanert et al., 1994; Patel and Martin, 1992). For these reasons, amorphous or glassy materials are thus among the more promising candidates of solid electrolytes because of their properties of single ion conduction and high ionic conductivities.

Oxide-based electrolytes are currently widely studied because of their stability in air, easy preparation, and their long shelf life(Cho et al., 2007; Jamal et al., 1999). However, they show a critical disadvantage which is their low ionic conductivity. Even still, so-called "LiPON" films formed from sputtering $\mathrm{Li}_{3} \mathrm{PO}_{4}$ in $\mathrm{N}_{2}$ atmospheres are currently one of the primary solid-state thin-film electrolytes in use because of these above mentioned advantages(Bates et al., 1993; Bates et al., 2000a; Bates et al., 2000b; Dudney, 2000; Neudecker et al., 2000; West et al., 2004; $\mathrm{Yu}$ et al., 1997). However, this easily prepared material has a relatively low $\mathrm{Li}^{+}$ ion conductivity of $\sim 10^{-6} \mathrm{~S} / \mathrm{cm}$ at $25{ }^{\circ} \mathrm{C}$ as compared to sulfide-based materials whose $\mathrm{Li}^{+}$ conductivities are in the range of $10^{-3} \mathrm{~S} / \mathrm{cm}$ at $25^{\circ} \mathrm{C}$ (Hayashi et al., 2003; Komiya et al., 2001; Minami et al., 2006; Mizuno et al., 2005).

Because lithium containing thio-materials show higher ionic conductivities than corresponding oxide materials, much research has been conducted on the use of the thiomaterials as solid electrolytes. Recently, sulfide materials have been investigated such as $\mathrm{SiS}_{2}$ (Aotani et al., 1994; Hayashi et al., 2002; Hirai et al., 1995; Kennedy, 1989), $\mathrm{GeS}_{2}$ (Haizheng et al., 2004; Kawamoto and Nishida, 1976; Pradel et al., 1985), $\mathrm{P}_{2} \mathrm{~S}_{5}$ (Hayashi et al., 2005; Mercier et al., 1981a; Mizuno et al., 2005; Murayama et al., 2004), and $\mathrm{B}_{2} \mathrm{~S}_{3}$ (Hintenlang and Bray, 1985; Wada et al., 1983). Among these sulfide materials, $\mathrm{GeS}_{2}$ is particularly attractive as a base material because it is less hygroscopic(Yamashita and Yamanaka, 2003), more oxidatively stable and enables a more electrochemically stable 
matrix for lithium-ion conduction to be prepared(Xia et al., 2009). While much research has been done on ion-conducting bulk sulfide glasses prepared by melt-quenching, only a few studies of thin-film ion conducting sulfides have been reported because of the difficulty in preparing them. For example, while Kim(Kim et al., 2005) et al. and Itoh et al.(Itoh et al., 2006) reported on the $\mathrm{Li}_{2} \mathrm{~S}+\mathrm{GeS}_{2}$ bulk glass system, detailed characterizations of thin-films in this system have not been reported so far. Several thin-film techniques such as pulsed laser deposition (PLD)(Jin et al., 2000; Tabata et al., 1994), radio frequency (RF) sputtering(Bates et al., 1993; Bates et al., 2000a; Bates et al., 2000b; Nakayama et al., 2003; Neudecker et al., 2000; Yu et al., 1997), e-beam evaporation(Bobeico et al., 2003; Wu et al., 2000), physical vapor deposition (PVD)(Kong et al., 2001; Narayan et al., 1992), and chemical vapor deposition (CVD)(Chhowalla et al., 2001) have been used to produce thin-films. Among these techniques, sputtering techniques have been shown to produce high quality thin-films. Furthermore, of the few reports that do exist on sulfide thin-films in the open literature, most show that the films tended to be strongly oxidized either during sputtering, caused possibly by leakage of the RF chamber, or by exposure to air after sputtering(Yamashita et al., 1996a). In addition, these thin-films were found to be $\mathrm{Li}$ deficient compared to that of the targets from which they were made(Yamashita et al., 1996a). Therefore, although sulfide films may have good potential in thin-film batteries, sulfide thin-films produced so far appear to be less than optimized and for this reason have found limited applications.

In order to investigate sulfide-based thin-films more extensively, lithium thio-germanate thin-films were carefully sputtered under well-controlled conditions in this study. Since $\mathrm{GeS}_{2}$-based materials are typically more stable in air than other sulfide materials, $\mathrm{GeS}_{2}$-based thin-film electrolytes for Li-ion thin-film batteries were grown by RF magnetron sputtering in Ar atmospheres. The starting materials, $\mathrm{GeS}_{2}$ and $\mathrm{Li}_{2} \mathrm{~S}$, and the target materials, $\mathrm{Li}_{2} \mathrm{GeS}_{3}$, $\mathrm{Li}_{4} \mathrm{GeS}_{4}$, and $\mathrm{Li}_{6} \mathrm{GeS}_{5}$, were characterized by X-ray diffraction to verify the phase purity of the targets used to produce thin-films. Further structural characterization of the starting materials, target materials, and their thin-films sputtered by RF sputtering in Ar atmospheres was conducted by Raman and IR spectroscopy to verify purity, contamination, and to examine the structures between targets and their thin-films. The surface morphology and the thickness of the thin-films were characterized by field emission scanning electron microscopy (FE-SEM).

The starting materials, target materials, and thin-films were carefully analyzed by x-ray photoelectron spectroscopy (XPS). To minimize contamination of the films produced in this work, every experimental step was performed carefully and in particular, the RF sputtering conditions were optimized to obtain consistency between target and thin-film compositions and to specifically produce films with near stoichiometric lithium concentrations. The starting materials, $\mathrm{Li}_{2} \mathrm{~S}$ and $\mathrm{GeS}_{2}$, the target materials, and thin-films were characterized by XPS for compositional and chemical shift analysis. In order to determine if a maximum conductivity in the $\mathrm{nLi}_{2} \mathrm{~S}+\mathrm{GeS}_{2}$ system exists, the $\mathrm{Li}_{2} \mathrm{~S}$ content ranged from $\mathrm{n}=1$ to $\mathrm{n}=4$, $50 \mathrm{~mol} \%$ to $80 \mathrm{~mol} \%$. Ionic conductivities of the thin-films were characterized by impedance spectroscopy. The ionic conductivities were measured over the temperature range from $-25{ }^{\circ} \mathrm{C}$ to $100{ }^{\circ} \mathrm{C}$ in $25^{\circ} \mathrm{C}$ increments and over the frequency range from $0.1 \mathrm{~Hz}$ to $1 \mathrm{MHz}$. Before we turn to a detailed description of this work, we first give an overview of 
the different electrodes that can be used with thin-film electrolytes and of the research progress to date on the chemistry and composition of thin-film electrolytes.

\section{Electrodes}

\subsection{Anodes}

As mentioned above in the introduction section, the development of advanced all-solid-state lithium-ion batteries with high energy densities is strongly desired because current lithium-ion batteries using liquid electrolytes potentially have safety issues(Machida et al., 2002; Machida et al., 2004). Because the battery performance strongly depends on the quality of the electrode materials, the electrode materials are very important in battery system. Although many different electrode materials have been developed for the conventional lithium-ion battery which used liquid electrolytes, many of the anode materials developed so far are not suitable for the solid-state lithium-ion batteries. Therefore, in this section, anode and cathode materials which are suitable for the solid-state lithium-ion battery are reviewed.

\subsubsection{Graphite/carbon}

Graphite/carbon materials have been commonly used as anode materials for the commercial lithium-ion battery using liquid electrolytes because graphite/carbon materials have many advantages including (1) a good cyclability, (2) a relatively large specific capacity of $\sim 370 \mathrm{mAh} / \mathrm{g}$, and (3) a low anode electrode potential of $\sim 0.2 \mathrm{~V}$ compared to the $\mathrm{Li} / \mathrm{Li}+$ electrode(Buiel and Dahn, 1999; Wu et al., 2003). Although carbon materials have some advantages for conventional Li-ion batteries, not all carbon materials are suitable for all-solid-state lithium-ion batteries with inorganic solid electrolytes. The reason for this is that during charge and discharge processes, the electrochemical lithium insertion into the anode materials, carbon materials, are not completely reversible in solid-state lithium-ion batteries with an inorganic electrolyte. In order to improve the performance of batteries, metallic lithium is very attractive compared to the graphite/carbon materials because metallic lithium has around ten times higher capacity than that of graphite/carbon materials.

\subsubsection{Lithium silicide}

Lithium silicide $\left(\mathrm{Li}_{4.4} \mathrm{Si}\right)$ is a good candidate as an anode material for all-solid-state lithium-ion batteries because $\mathrm{Li}_{4.4} \mathrm{Si}$ has a large theoretical specific capacity of $\sim 4000 \mathrm{mAh} / \mathrm{g}$, has a high negative potential close to that of lithium metal, and $\mathrm{Si}$ is very abundant and is a non-toxic material (Armand and Tarascon, 2008; Lee et al., 2001). However, $\mathrm{Li}_{4.4} \mathrm{Si}$ has a severe volume expansion of over $300 \%$ for the $\mathrm{Li}_{4.4} \mathrm{Si}$ phase during charge and discharge processes. Thus, in its common form, the material shows poor cyclability compared to graphite and has barriers for commercial application (Kubota et al., 2008). Four different lithium silicides, $\mathrm{Li}_{4.4} \mathrm{~S}, \mathrm{Li}_{3.25} \mathrm{Si}, \mathrm{Li}_{2.33} \mathrm{Si}$, and $\mathrm{Li}_{1.71} \mathrm{Si}$, as intermetallic phases have been reported in Li-Si system(Sharma and Seefurth, 1976).

\subsubsection{Lithium metal}

Lithium metal as an anode material has high energy density and it has been recognized as the best candidate for lithium-ion batteries(Tarascon and Armand, 2001). While dendrite 
formation during cycling is found with liquid electrolytes, lithium metal does not form dendrites in all solid-state lithium-ion batteries. In solid-state batteries, the major challenges are interface resistances and electrochemical stability at the contact area between the anode and electrolyte. Further, extensive effort is demanded before lithium metal is applied to commercial all solid state lithium ion batteries.

\subsection{Cathode}

While anode materials play an important role in supporting the lithium source, the cathode materials also plays an important role in supporting the reducible/oxidizable ion for secondary lithium-ion batteries. There are key requirements for good cathode materials to be used successfully in rechargeable lithium-ion batteries(Whittingham, 2004). The cathode materials should react with lithium metal in a reversible manner, with a high free-energy of formation and react very rapidly both on insertion and removal. In addition, these materials need to be a good electrical conductors, be electrochemically stable, have a low cost, and need to be environmentally safe (Whittingham, 2004). Until now, many cathode materials have been studied. In this section, some of the more representative cathode materials are reviewed.

\subsubsection{Vanadium pentoxide $\left(\mathrm{V}_{\mathbf{2}} \mathrm{O}_{5}\right)$}

Vanadium pentoxide, $\mathrm{V}_{2} \mathrm{O}_{5}$, has been studied for three decades(Dickens et al., 1979; Whittingham, 1976). $\mathrm{V}_{2} \mathrm{O}_{5}$ as a cathode material is an alternative because of its low cost, plentiful resources, and greater safety compared to commercial cathodes such as $\mathrm{LiCoO}_{2}$ and $\mathrm{LiNiO}_{2}$ (Wang and Cao, 2008). The main disadvantages of the $\mathrm{V}_{2} \mathrm{O}_{5}$ material are its low capacity, low conductivity, and poor structural stability(Li et al., 2007). Recently, the $\mathrm{V}_{2} \mathrm{O}_{5}$-based material, polyaniline (PAN) $-\mathrm{V}_{2} \mathrm{O}_{5}$ composites have been extensively studied to improve conductivity, cyclabilty, and coulombic efficiency of the electrode materials used in lithium batteries(Malta and Torresi, 2005; Pang et al., 2005).

\subsubsection{Lithium cobalt oxide $\left(\mathrm{LiCoO}_{2}\right)$}

Lithium cobalt oxide, $\mathrm{LiCoO}_{2}$, cathode material was discovered by John Goodenough in 1980 when he worked at Oxford University(Mizushima et al., 1980). Research on $\mathrm{LiCoO}_{2}$ material has been widely done because of its high energy density and good cyclability(Wang et al., 1999) and relatively high theoretical capacity of $272 \mathrm{mAh} / \mathrm{g}$. $\mathrm{LiCoO}_{2}$ cathode material is attractive because of its high energy density and reversible lithium-ion intercalation(Chiang et al., 1998; Kumta et al., 1998). Furthermore, $\mathrm{LiCoO}_{2}$ material has a layer structure which can be suitable for the accommodation of the large changes of the lithium contents. Therefore, it can be cycled more than 500 times with 80-90\% capacity retention (Patil et al., 2008). Thin-film $\mathrm{LiCoO}_{2}$ cathode materials also show good power density when discharged between $3.0 \mathrm{~V}$ and $4.2 \mathrm{~V}$ (Kim et al., 2000) because of the layered $\mathrm{LiCoO}_{2}$ structure. Amatucci et al.(Amatucci et al., 1996) reported that $\mathrm{LiCoO}_{2}$ can be reversibly form the $\mathrm{Li}$-ion and $\mathrm{CoO}_{2}$. In addition, the preparation of $\mathrm{LiCoO}_{2}$ is very facile over other comparable materials. For these reasons, it became the most common cathode material in lithium batteries. 
However, cobalt is relatively expensive compared to other elements such as $\mathrm{Ni}, \mathrm{Mn}$, and V. In order to make it cheaper and improve the reversible capacity, Yonezawa et al.(Yonezawa et al., 1998) and Huang et al.(Huang et al., 1999) applied doping materials such as fluorine, magnesium, aluminum, nickel, copper or tin. If $\mathrm{LiF}$ is doped, the reversible capacity improved compared to pure $\mathrm{LiCoO}_{2}($ Yonezawa et al., 1998). If $\mathrm{Al}$ is incorporated partially to substitute for cobalt, the working and open voltages increased. Huang et al. reported that the reversible capacity of $\mathrm{LiAl}_{0.15} \mathrm{Co}_{0.85} \mathrm{O}_{2}$ reached up to $160 \mathrm{mAh} / \mathrm{g}$ without volume change after 10 cycles(Huang et al., 1999). Especially, self-discharge effects of the thin-film batteries using $\mathrm{LiCoO}_{2}$ cathodes are negligible (Dudney, 2005). Thus, thin-film batteries using $\mathrm{LiCoO}_{2}$ cathode can hold full charge for three years(Dudney, 2005).

\subsubsection{Lithium manganese oxide $\left(\mathrm{LiMn}_{2} \mathrm{O}_{4}\right)$}

Lithium manganese oxide, $\mathrm{LiMn}_{2} \mathrm{O}_{4}$, is an attractive cathode material and has been widely studied because the material has advantages from ecological and economical perspectives as well as easy preparation (Kang and Goodenough, 2000; Lee et al., 2004; Liu and Shen, 2003; Ohzuku et al., 1991). However, $\mathrm{LiMn}_{2} \mathrm{O}_{4}$ has a serious drawback. Before cycling, the structure of the $\mathrm{LiMn}_{2} \mathrm{O}_{4}$ is cubic. Then, on cycling, the spinel structure is destroyed due to a cubic-tetragonal phase transition induced by Jahn-Teller distortion (David et al., 1987; Gummow et al., 1993; Gummow and Thackeray, 1994). For this reason, batteries with $\mathrm{LiMn}_{2} \mathrm{O}_{4}$ cathodes show capacity loss and poor cyclability(Gummow et al., 1994; Myung et al., 2000). Pure $\mathrm{LiMn}_{2} \mathrm{O}_{4}$ has been improved by doping. If chromium is doped into $\mathrm{LiMn}_{2} \mathrm{O}_{4}$, it can form $\mathrm{Li}_{1+\times} \mathrm{Mn}_{0.5} \mathrm{Cr}_{0.5} \mathrm{O}_{2}$ and the doped $\mathrm{Li}_{1+} \mathrm{Mn}_{0.5} \mathrm{Cr}_{0.5} \mathrm{O}_{2}$ reveals improved capacity and cyclability(Sigala et al., 1995). It can be assumed that Mn plays an important role to stabilize the structure of the chromium oxide. However, chromium materials are toxic and expensive. Therefore, in order to fabricate successfully stabilized layer structural framework, the doping of other elements into $\mathrm{LiMn}_{2} \mathrm{O}_{4}$ has been studied.

\subsubsection{Lithium nickel oxide $\left(\mathrm{LiNiO}_{2}\right)$}

Because $\mathrm{LiNiO}_{2}$ is cheaper than $\mathrm{LiCoO}_{2}$ and the redox potential is higher than that of $\mathrm{LiCoO}_{2}$, The $\mathrm{LiNiO}_{2}$ material has become an attractive as a cathode material for Li-ion batteries(Campbell et al., 1990). The structure of the $\mathrm{LiNiO}_{2}$ is layered similar to $\mathrm{LiCoO}_{2}$ (Zhecheva and Stoyanova, 1993). The layered $\mathrm{LiNiO}_{2}$ structure has a wide homogeneity range, $\mathrm{Li}_{x} \mathrm{Ni}_{2-\mathrm{x}} \mathrm{O}_{2}(0.6<\mathrm{x}<1)$ (Bronger et al., 1964). Upon cycling, the capacity of the materials fades because $\mathrm{Ni}^{2+}$ ions migrate to $\mathrm{Li}^{+}$sites. The appearance of $\mathrm{Ni}^{2+}$ in the $\mathrm{Li}^{+}$ sites obstructs $\mathrm{Li}^{+}$diffusion and the lithium-ion transfer during cycling( $\mathrm{Li}$ et al., 1992). For this reason, the $\mathrm{LiNiO}_{2}$ battery shows poor cycle performance compared to $\mathrm{LiCoO}_{2}(\mathrm{Dahn}$ et al., 1991). $\mathrm{LiNiO}_{2}$ has some drawbacks such as being unstable in the overcharge state as well as easy decomposition at high temperature. Furthermore, lithium oxide contents in the $\mathrm{LiNiO}_{2}$ decrease when heat treatment is performed due to the volatility of $\mathrm{Li}_{2} \mathrm{O}$. The $\mathrm{Li}$ deficient defect structure results in gradual collapse of oxide structure during cycling and the specific charge decreases during cycling of the $\mathrm{LiNiO}_{2}$ electrode(Hirano et al., 1995). In order to improve the performance of the $\mathrm{LiNiO}_{2}$ structure, many researchers have studied this material using doping elements such as $\mathrm{Co}, \mathrm{Ti}, \mathrm{Mn}, \mathrm{Al}, \mathrm{Mg}, \mathrm{Fe}, \mathrm{Zn}, \mathrm{Ga}, \mathrm{Sb}$, and $\mathrm{S}$ (Chang et al., 2000; Chowdari et al., 2001; Cui et al., 2011; Gao et al., 1998; Nishida et al., 1997; Park 
et al., 2005; Park and Sun, 2003; Pouillerie et al., 2000; Reimers et al., 1993). The reversible capacity of $\mathrm{LiNi}_{0.75} \mathrm{Ti}_{0.125} \mathrm{O}_{2}$ reached up to $190 \mathrm{mAh} / \mathrm{g}$ (Gao et al., 1998). Therefore, from this point of view, the doped $\mathrm{LiNiO}_{2}$ can be a good candidate as a cathode material for secondary Li-ion batteries; however, safety is a serious concern.

\subsubsection{Lithium iron phosphate $\left(\mathrm{LiFePO}_{4}\right)$}

Lithium iron phosphate, $\mathrm{LiFePO}_{4}$, was reported by John Goodenough's research group in 1996, as a cathode material for rechargeable lithium batteries(Padhi et al., 1997). Conventional cathode materials, $\mathrm{LiCoO}_{2}$ and $\mathrm{LiNiO}_{2}$, have drawbacks such as the high cost, toxicity, safety issues, and electrochemically instability. $\mathrm{LiFePO}_{4}$ is a promising candidate for secondary lithium-ion batteries because of its relatively high energy density, low cost, good safety, and high thermal stability compared to conventional cathode materials(Padhi et al., 1997). However, there is a key barrier in that $\mathrm{LiFePO}_{4}$ has an intrinsically low electrical conductivity of $10^{-9}$ to $10^{-10} \mathrm{~S} / \mathrm{cm}$ (Andersson et al., 2000; Barker et al., 2003; Padhi et al., 1997). Therefore, early studies on $\mathrm{LiFePO}_{4}$ showed that it was not the best cathode material over other conventional cathode materials. These problems were resolved later by reducing the particle size, doping using cations of materials such as $\mathrm{Al}, \mathrm{Nb}$, and $\mathrm{Zr}$, and coating the $\mathrm{LiFePO}_{4}$ particles using a conductive carbon material(Huang et al., 2001; Prosini et al., 2001; Shi et al., 2003; Yamada et al., 2001). By using these methods, greatly improved electrochemical response and full capacity of $\mathrm{LiFePO}_{4}$ was obtained with prolonged cycle life. Recently, $\mathrm{LiFePO}_{4}$ can be used up to $90 \%$ of its theoretical capacity, $165 \mathrm{mAh} / \mathrm{g}$, and at high rate capabilities(Yamada et al., 2001). Thus, optimized $\mathrm{LiFePO}_{4}$ is a good candidate as a cathode material for the solid-state thin-film batteries.

\section{Electrolytes}

Among the three components, anode, cathode, and electrolyte, in a battery system, battery performance strongly depends on the performance of the electrolyte. The basic requirements of an appropriate electrolyte for lithium-ion batteries are high ionic conductivity, electrochemical and thermal stability, and good performance at low and high temperatures. Because liquid electrolytes have a higher ionic conductivity compared to polymer and solid electrolytes, they have been widely used. However, liquid electrolytes have strong ionic conductivity temperature dependence and can have safety issues related to the flammability of the organic liquid. Recently, solid-state lithium secondary batteries have attracted much attention because the replacement of conventional liquid electrolyte with an inorganic solid electrolyte may improve the safety and reliability of lithium batteries utilizing high capacity lithium metal anodes(Jones and Akridge, 1992). There are two types of solid state electrolytes; one is thin-film electrolytes grown by RF sputtering(Bates et al., 1993; Bates et al., 2000a; Bates et al., 2000b; Dudney et al., 1999; Neudecker et al., 2000; Seo and Martin, 2011a, b, c; Yu et al., 1997) or PLD(Jin et al., 2000; Tabata et al., 1994) etc. and the other is bulk electrolytes fabricated by typically using melting processes. All-solid-state thin-film batteries using inorganic amorphous electrolytes such as LiPON have been reported and LiPON shows excellent cyclability, over 50,000 cycles, at room temperature(Bates et al., 1993; Bates et al., 2000a; Bates et al., 2000b; Dudney et al., 1999; Neudecker et al., 2000; Yu et al., 1997). However, bulk type batteries using bulk electrolytes have an advantage of improving 
cell capacity by the addition of large amounts of active materials to the cell. For both the thin-film and bulk batteries, $\mathrm{Li}_{2} \mathrm{~S}$ based electrolytes are promising because of their high ionic conductivities compared to oxide electrolytes. In the next section, we report recent data of the thin-film electrolytes for the solid-state batteries.

\subsection{Polymer electrolytes}

Polymer electrolytes for use in lithium batteries were rapidly developed in the 1970s(Fenton et al., 1973). It was found that these materials could offer a safer battery than liquid electrolytes which are corrosive, flammable, or toxic. In recent decades, polymer electrolytes have been widely studied including polyethyleneoxide (PEO)(Appetecchi et al., 2003), polyacrylonitrile (PAN)(Yu et al., 2001), polymethylmethacrylate (PMMA)(Rajendran and Uma, 2000), and polyvinylidenefluoride (PVDF)(Saunier et al., 2004). However, the ionic conductivity of these polymer electrolytes is still too low at room temperature for commercial batteries. In addition, the primary concerns with these electrolytes involve their reactivity with a lithium metal as an anode. Their reactivity with lithium poses safety concerns because lithium dendrites can grow towards the cathode and ultimately shortcircuit the cell. For this reason, gel-type polymer electrolytes were developed and the electrolytes show improved ionic conductivity compared to conventional polymer electrolytes, but they still have lower ionic conductivities than those of liquid electrolytes. The gel-type polymer electrolytes have ionic conductivity of $\sim 10^{-4} \mathrm{~S} / \mathrm{cm}$ at room temperature. In the gel-type polymer electrolytes, the liquid element can be trapped in polymer matrix so the leakage problems associated with liquid electrolytes can be resolved. The low conductivity of the polymer/gel polymer electrolytes can be overcome by introducing inorganic ceramic particles to form a composite material that is more "solid". These materials have conductivities two or three orders of magnitude lower than aqueous electrolytes. However, thin polymer films on the order of $100 \mu \mathrm{m}$ thick can compensate for their diminished conductivities(Birke et al., 1999). There is also the opportunity of increasing the operating temperature of the cell to around $90{ }^{\circ} \mathrm{C}$. Therefore, optimized thin polymer electrolytes can be promising electrolytes for the thin-film solid-state batteries.

\subsection{Solid-state electrolytes}

While commercial cells will continue to be fabricated using organic polymeric electrolytes due to their ease of fabrication and low cost, solid-state electrolytes will also attract attention for their possible use in special applications. Solid-state electrolytes are attractive because they provide a hard surface that is capable of suppressing side reactions and inhibiting dendritic growth of lithium that is capable of short-circuiting a cell(Schalkwijk and Scrosati, 2002). However, one disadvantage of these electrolytes is their potential to form cracks or voids if there is poor adhesion to the electrode materials. In order to successfully fabricate all-solid-state lithium batteries with good performance, the design of the electrodes and electrolytes are important.

A number of candidate materials have been investigated for use as solid electrolytes in batteries. The most attractive candidates to date are glassy materials. These electrolytes have many advantages over their crystalline counterparts such as physical isotropy, absence of grain boundaries, good compositional flexibility, and good workability. The anisotropy and 
grain boundaries present in crystalline materials lead to resistive loss, decreasing cell efficiency, as well as chemical attack, raising safety concerns. A number of different systems have been explored and are discussed specifically below.

\subsubsection{Oxide glasses}

Oxide glass electrolytes for solid-state batteries have been widely studied because they have the primary advantage of being relatively stable in air allowing for ease of fabrication. However, oxide glasses have received less attention for their use as electrolyte materials because they exhibit very low ionic conductivities and high activation energies. The best of the oxide materials appears to be those glasses with mixed formers such as $\mathrm{SiO}_{2}$ and $\mathrm{B}_{2} \mathrm{O}_{3}$ (Lee et al., 2002; Nogami and Moriya, 1982; Zhang et al., 2004). These glasses have a conductivity at room temperature on the order of $\sim 10^{-7} \mathrm{~S} / \mathrm{cm}$. These materials might prove promising if produced into thin-films. However, chemistries with a higher ionic conductivity are more desirable. Sulfide materials, discussed in more detail below, are of interest for this reason. In terms of conductivity, it is clear that oxide glasses have significantly lower conductivities than those of sulfide materials(Boukamp and Huggins, 1978; Elmoudane et al., 2000; Ito et al., 1983; Mercier et al., 1981b; Murayama et al., 2004).

\subsubsection{Oxinitride glasses}

The most commercially viable material in this category is the lithium phosphorus oxynitride (LiPON) glass. This material was first discovered and reported in the 1980s by Marchand(Marchand et al., 1988) and Larson(Larson and Day, 1986). These materials were not thin-films but bulk glass materials. In addition, their properties were not fully characterized until Oak Ridge National Laboratory (ORNL) reported LiPON thinfilms(Bates et al., 1993; Bates et al., 2000a; Bates et al., 2000b; Dudney, 2000; Dudney, 2005; Dudney et al., 1999; Neudecker et al., 2000; Yu et al., 1997). The LiPON thin-films were deposited using a high purity lithium phosphate, $\mathrm{Li}_{3} \mathrm{PO}_{4}$, target by $\mathrm{RF}$ magnetron sputtering technique in nitrogen atmosphere. It was found that the resulting thin-film with a typical composition of $\mathrm{Li}_{2.9} \mathrm{PO}_{3.3} \mathrm{~N}_{0.36}$ contained 6 at $\%$ nitrogen. This additional nitrogen was found to enhance the ionic conductivity at room temperature from $\sim 10^{-8}$ $\mathrm{S} / \mathrm{cm}$ in the starting $\mathrm{Li}_{3} \mathrm{PO}_{4}$ target to a value of $\sim 10^{-6} \mathrm{~S} / \mathrm{cm}$. Furthermore, these films were found to be highly stable in contact with metallic lithium. It is believed that a thin passivating layer of $\mathrm{Li}_{3} \mathrm{~N}$ is formed between the lithium and electrolyte which prevents lithium dendrite growth, but allows ion conduction. The nitrogen was found to substitute for oxygen and form 2 and 3-coordinated nitrogen groups, effectively crosslinking the structure. The schematic of the structural units of LiPON are shown Figure (2). This crosslinking is believed to decrease the electrostatic energy of the overall network, allowing for faster ion conduction. Thin-film batteries comprised of $\mathrm{Li}-\mathrm{LiCoO}_{2}$ cells and Li-LiMn $\mathrm{O}_{4}$ cells have been fabricated using the LiPON electrolyte at ORNL(Bates et al., 1993; Bates et al., 2000a; Bates et al., 2000b; Dudney, 2000; Dudney, 2005; Dudney et al., 1999; Neudecker et al., 2000; Park et al., 2007; Yu et al., 1997). Nam et al. reported LiPON using $\mathrm{V}_{2} \mathrm{O}_{5}$ cathode materials(Jeon et al., 2001). These types of batteries are being commercialized and target for applications in implantable medical devices, CMOS-based integrated circuits, and RF identification (RFID) tags for inventory control and anti-theft protection. 


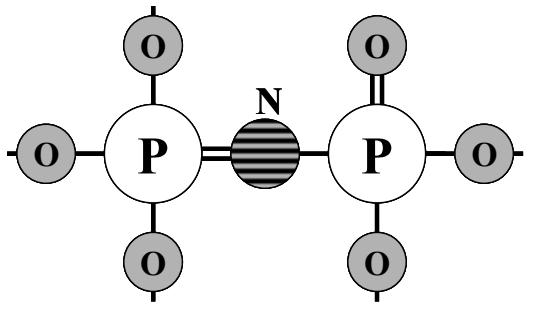

(a)

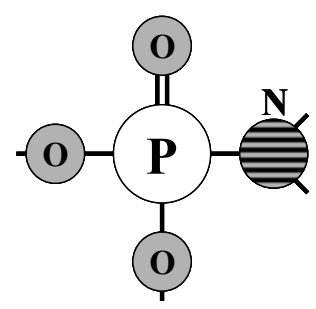

(b)

Fig. 2. Proposed structural units present in LIPON sputtered films. (a) two-coordinated bridging nitrogen unit and (b) three-coordinated nitrogen unit.

\subsubsection{Sulfide glasses}

Sulfide glasses were first reported on in the 1980s(Kennedy, 1989; Mercier et al., 1981a; Zhang and Kennedy, 1990). These glasses were based on $\mathrm{SiS}_{2}, \mathrm{P}_{2} \mathrm{~S}_{5}$, and $\mathrm{B}_{2} \mathrm{~S}_{3}$ and are doped with an alkali sulfide such as lithium sulfide. It was found that these materials have exceptional conductivities, $\sim 10^{-3} \mathrm{~S} / \mathrm{cm}$, at room temperature. This is attributed primarily to the larger ionic radius of sulfur and its high atomic polarizability(Kim et al., 2006). This is believed to create weaker covalent bonds between the sulfur and the lithium ions. As a result, the potential energy barrier that must be overcome is decreased, and lithium-ion conduction is facilitated. Unfortunately, these glasses have not been widely used because they are highly reactive in air/moisture and corrosive with silica containers. A high quality, low $\mathrm{O}_{2}$ and $\mathrm{H}_{2} \mathrm{O}$, glovebox is absolutely necessary to fabricate such glasses without contamination.

The thin-films related to the $\mathrm{Li}_{2} \mathrm{~S}-\mathrm{GeS}_{2}-\mathrm{Ga}_{2} \mathrm{~S}_{3}$ glass system have recently been prepared using RF sputtering(Yamashita and Yamanaka, 2003; Yamashita et al., 1996b). Successfully deposited films were produced using this method, however, the authors reported that the ionic conductivities of the thin-films were diminished compared to that of the target material. This was a result of the films being deficient in lithium and enriched in germanium from the XPS composition analysis of the films. In addition, the thin-films were contaminated by $\mathrm{O}_{2}$ during sputtering due to the leakage of the RF chamber. Although the ionic conductivities of the sulfide materials are higher than oxide materials, if the sulfide thin-films exhibit lithium deficiency and contamination, there are few benefits of sulfide materials.

\subsubsection{Oxy-sulfide glasses}

Efforts to combine the advantages of oxide and sulfide glasses have resulted in the research of a class of oxy-sulfide materials(Hayashi et al., 1996; Kondo et al., 1992; Takada et al., 1996). It was found that adding a small amount, approximately 5 mole \%, of different lithium metal oxides to a base sulfide glass, improved the conductivity over $10^{-3}$ S/cm(Minami et al., 2008; Ohtomo et al., 2005). Furthermore, the stability of the structure was observed to improve from thermal analysis results. Structural analysis of these materials has demonstrated that the oxygen typically occupies a bridging anion site, 
leaving sulfur at the non-bridging sites for lithium mobility. Some solid-state batteries have been fabricated using these oxy-sulfide compositions, and initial results appear to indicate good electrochemical stability (Hayashi et al., 2010; Minami et al., 2011; Ohtomo et al., 2005).

\subsubsection{Thio-nitride glasses}

Lithium nitride $\left(\mathrm{Li}_{3} \mathrm{~N}\right)$ materials are somewhat attractive as a solid electrolyte because of their high ion conductivity, $2-4 \times 10^{-4} \mathrm{~S} / \mathrm{cm}$ at $25^{\circ} \mathrm{C}$ (Lapp et al., 1983). The single crystal $\mathrm{Li}_{3} \mathrm{~N}$ has an impressive high ionic conductivity of $1.2 \times 10^{-3} \mathrm{~S} / \mathrm{cm}$ at room temperature(Rabenau, 1982). However, it is impossible to use $\mathrm{Li}_{3} \mathrm{~N}$ itself as an electrolyte in secondary batteries because $\mathrm{Li}_{3} \mathrm{~N}$ decomposes at low voltage (Yonco et al., 1975). For this reason, thio-nitride glasses have been studied with high ionic conduction(Iio et al., 2002; Sakamoto et al., 1999). The motivation behind these materials comes from the fact that doping nitrogen into oxide systems improved the ionic conductivity(Unuma and Sakka, 1987; Wang et al., 1995c). Furthermore, doping of nitrogen into oxide glasses has been found to improve the hardness and chemical durability (Sakka, 1986).

\section{All-solid-state thin-film batteries}

\subsection{History of thin-film batteries}

All-solid-state thin-film batteries were reported first by Hitachi Co. Ltd in Japan in 1982. The $\mathrm{TiS}_{2}$ cathode material was prepared by chemical vapor deposition (CVD), a $\mathrm{Li}_{12} \mathrm{Si}_{3} \mathrm{P}_{2} \mathrm{O}_{20}$ electrolyte was grown by radio frequency (RF) sputtering, and a lithium metal anode material was deposited by a vacuum evaporation(Kanehori et al., 1986; Miyauchi et al., 1983). NTT Co. also reported thin-film batteries using a $\mathrm{Li}_{12} \mathrm{Si}_{3} \mathrm{P}_{2} \mathrm{O}_{20}$ electrolyte with $\mathrm{LiCoO}_{2}$ or $\mathrm{LiMnO}_{2}$ cathode materials grown by RF sputtering(Ohtsuka et al., 1990; Ohtsuka and Yamaki, 1989; Yamaki et al., 1996). The performance of the thin-film batteries was not as good as current thin-film batteries.

In 1980s, Union Carbide Corporation and Eveready Battery Co., Ltd. in USA developed thin-film batteries using sulfide glass electrolytes, $\mathrm{Li}_{4} \mathrm{P}_{2} \mathrm{~S}_{7}$ or $\mathrm{Li}_{3} \mathrm{PO}_{4}-\mathrm{P}_{2} \mathrm{~S}_{5}$, and $\mathrm{Li}$ metal anode or LiI anode(Akridge and Vourlis, 1986, 1988). They improved the battery performance in $1990 \mathrm{~s}$ to reach over 1000 cycle performance between $1.5 \mathrm{~V}$ and $2.8 \mathrm{~V}$ and 10 to 135 $\mu \mathrm{A} / \mathrm{cm}^{2}$ (Jones and Akridge, 1996). Bellcore Co., Ltd. also developed thin-film batteries using a $\mathrm{LiMnO}_{2}$ cathode, lithium metal as an anode, and lithium borophosphate (LiBP) or lithium phosphorus oxynitride (LiPON) glass as an electrolyte(Shokoohi et al., 1991). The cell showed over 150 cycles with 3.5 4.3 $\mathrm{V}$ and $70 \mu \mathrm{A} / \mathrm{cm}^{2}$.

Recently, Bates and Dudney et al. at Oak Ridge National Laboratory (ORNL) reported significant progress on LiPON-based thin-film batteries which were produced by an RF sputtering technique(Bates et al., 1993; Bates et al., 2000a; Bates et al., 2000b; Dudney et al., 1999; Wang et al., 1995a; Wang et al., 1995b; Wang et al., 1995c; Yu et al., 1997). In order to fabricate LiPON thin-film batteries, the metallic anode was produced by vacuum evaporation and anode and cathodes were produced by RF sputtering. The LiPON thin-film batteries are very stable in air compared to lithium oxide or sulfide based batteries in spite of LiPON's low ionic conductivity of $\sim 10^{-6}(\mathrm{~S} / \mathrm{cm})$. The LiPON thin-films reported by ORNL showed very good performance between $2-5 \mathrm{~V}$ and over 10,000 cycles. Furthermore, ORNL 
reported also a Li-free thin-film battery with an in-situ plated Li anode on copper electrode (Neudecker et al., 2000).

LiPON is now known as a standard electrolyte for the thin-film batteries and it has been widely studied by a number of research groups. Park et al. in Korea reported "mesa-type" all-solid-state LiPON thin-film battery using a $\mathrm{LiMn}_{2} \mathrm{O}_{4}$ cathode(Park et al., 1999). Baba et al. in Japan reported also LiPON thin-film batteries using a $\mathrm{Li}_{\mathrm{x}} \mathrm{V}_{2} \mathrm{O}_{5}$ anode material and $\mathrm{V}_{2} \mathrm{O}_{5}$ or $\mathrm{LiMn}_{2} \mathrm{O}_{4}$ cathode materials produced by RF sputtering(Baba et al., 2001; Baba et al., 1999; Komaba et al., 2000).

Jourdaine et al. in France reported thin-film batteries produced by RF sputtering. They successfully fabricated the cell using metallic lithium as an anode, $\mathrm{Li}_{2} \mathrm{O}_{-}-\mathrm{B}_{2} \mathrm{O}_{3}-\mathrm{P}_{2} \mathrm{O}_{5}$ or $\mathrm{Li}_{2} \mathrm{O}-$ $\mathrm{B}_{2} \mathrm{O}_{3}$ glasses as electrolytes, and $\mathrm{V}_{2} \mathrm{O}_{5}-\mathrm{TeO}_{2}$ or $\mathrm{V}_{2} \mathrm{O}_{5}-\mathrm{P}_{2} \mathrm{O}_{5}$ as cathodes, respectively(Jourdaine et al., 1988).

\subsection{Thin-film techniques}

There are many vapor deposition techniques that can be employed in order to produce thinfilm materials. These include simple heating of a source material, laser-induced vaporization, or bombarding the material with energetic ions. All of these techniques are performed under vacuum and rely on the kinetic theory of gases in order to understand their behavior.

\subsubsection{Pulsed laser deposition (PLD)}

Pulsed laser deposition (PLD) involves using a laser beam to vaporize the surface of a target material(Chrisey and Hubler, 1994). One of the most common lasers used is the KrF excimer laser, operating at $248 \mathrm{~nm}$ with the following parameters: a pulse on the order of $25 \mathrm{~ns}$, a power density of $2.4 \times 10^{8} \mathrm{~W} / \mathrm{cm}^{2}$, and a repetition rate of $50 \mathrm{~Hz}$. In general, the PLD process can be divided into four stages(Chrisey and Hubler, 1994). First, the laser beam is focused onto the target material. The elements in the target are rapidly heated to their evaporation temperature where there are sufficiently high flux densities over a short pulse duration. This ablation process involves many complex physical phenomena such as collisional, thermal and electronic excitation, exfoliation and hydrodynamics. Second, the ablated target elements move towards the substrate according to the laws of gas-dynamics. In the third stage, the high energy atoms bombard the substrate surface where a collision region is formed between the incident flow and the sputtered atoms. A film begins to grow after a thermalized region develops and when the condensation rate is higher than the rate of sputtered atoms. Finally, nucleation and growth of a thin-film occurs on the substrate. This step depends on many factors such as the density, energy, ionization degree, and the temperature of the substrate. PLD has some advantage over other techniques in that the stoichiometry of the target can be retained in the deposition film and many different materials can be deposited, and can be easily handled compared to other techniques such as CVD and ion implantation techniques(Bao et al., 2005; Kaczmarek, 1996). On the other hand, it has some disadvantages such as the deposition of droplets(Yoshitake et al., 2001), the splashing or the particulates deposition on the thin-film, and lower energy density and lower deposition rate compared to other techniques(Willmott and Huber, 2000). 


\subsubsection{Radio frequency (RF) sputtering}

Sputtering is a technique whereby energetic ions from a plasma are used to bombard a target (which is the cathode of the discharge), and ejecting atoms into the plasma. These atoms then impinge upon the substrate (the anode) and form a coating. Additionally, a magnet can be added to these two setups in order to enhance the deposition rates. RF magnetron sputtering is a reliable technique used to deposit many different types of films, including electrically insulating samples. A high-voltage RF source at a frequency of typically $13.56 \mathrm{MHz}$ is used to ionize a sputtering gas which produces the plasma(Yamashita et al., 1999). The ionized gas then bombards the target where multiple collisions take place, releasing atoms of the target material into the plasma. These atoms condense upon the substrate which is placed in front of the target(Nalwa, 2002). A permanent magnet is added to the sputtering gun in order to enhance the deposition rate. This is done by the trapping of electrons from a Hall effect near the target surface(Nalwa, 2002). This magnet creates lines of magnetic flux that are perpendicular to the electric field or parallel to the target surface. This static magnetic field retains secondary electrons in that region which drift in a cycloidal path on the target and increase the number of collisions that occur.

While many different thin-film deposition techniques could be used in this research, RF magnetron sputtering (RFMS) has been chosen as the technique of choice. The most important reasons for selecting RFMS as the technique of choice are given here(Dudney et al., 1999; Souquet and Duclot, 2002). First, there is no need in the project to produce thick films. To produce a protective barrier for lithium metal anodes, a layer is needed and only needs to be thick enough so that it does not have large numbers of pin holes that will lead to failure of the anode. A layer 50 to $5000 \AA$ is thought to be thick enough. Such layers can easily be produced by RFMS. Secondly, in the thin-film lithium battery research, there is no need for thick films and films 500 to $10,000 \AA$ are thick enough, which are again attainable with sputtering techniques. In addition, sputtering can be done within the confines of a sealed glovebox, can be used with multiple targets and film chemistries, can be used to produce very uniform films of high compositional integrity, and produces films with excellent adherence to the substrate. Finally, it is possible to deposit insulator films through RF reaction sputtering at rates higher than those of DC methods(Davidse, 1967).

\subsubsection{Chemical Vapor Deposition (CVD)}

Chemical Vapor Deposition (CVD) process is related to transform gaseous molecules, precursor, by chemical reactions in the thin-film or power on the substrate(Mount, 2003). CVD processing is usually used to apply various fields such as integrated circuits, optoelectronic devices and sensors, micro-machines, and fine metal and ceramic powders. CVD has many advantages compared to physical vapor deposition (PVD) techniques such as sputtering and molecular beam evaporation. While PVD processes may not give complete coverage due to a shadowing effect, CVD can be allowed to coat thin-films of three dimensional structures with large aspect ratios. The deposition rates of the CVD are several times higher than that of PVD. In addition, ultra high vacuum is not needed and high purity film can be produced by CVD process. However, there are some disadvantages of the CVD process. High temperatures of the deposition temperature, over $600{ }^{\circ} \mathrm{C}$, are not suitable for 
already grown thin-films on substrates. CVD precursors are sometimes dangerous and toxic and many precursors for CVD, for example metal organic chemical vapor deposition (MOCVD) precursors, are very expensive.

\subsection{Recent results for the lithium thio-germanate thin-film electrolytes}

\subsubsection{X-ray diffraction of the starting materials and targets}

In this study, $\mathrm{GeS}_{2}$ and $\mathrm{Li}_{2} \mathrm{~S}$ as starting materials were used to synthesize the target material. To verify the phase purity, XRD pattern of $\mathrm{GeS}_{2}$ glass powder, $\mathrm{Li}_{2} \mathrm{~S}$ crystalline powder and three target materials are shown in Figure (3). While $\mathrm{GeS}_{2}$ glass powder is verified to be amorphous, $\mathrm{Li}_{2} \mathrm{~S}$ powder shows several sharp peaks. The XRD pattern of the $\mathrm{Li}_{2} \mathrm{~S}$ powder closely matches the JCPDS data(Cunningham et al., 1972). From the JCPDS data, it is verified that the system and space group of $\mathrm{Li}_{2} \mathrm{~S}$ powder are face-centered cubic and $\mathrm{Fm}-3 \mathrm{~m}$, respectively (Cunningham et al., 1972).

The $\mathrm{Li}_{2} \mathrm{GeS}_{3}$ target shows an XRD amorphous pattern without dominant peaks because the melt-quenching technique combined with its $50 \% \mathrm{GeS}_{2}$ glass former composition are sufficient to make this phase amorphous on cooling during preparation. The XRD patterns of the $\mathrm{Li}_{4} \mathrm{GeS}_{4}$ and $\mathrm{Li}_{6} \mathrm{GeS}_{5}$ targets, on the other hand, are polycrystalline and show sharp peaks because the $\mathrm{Li}_{4} \mathrm{GeS}_{4}$ and $\mathrm{Li}_{6} \mathrm{GeS}_{5}$ target contain only $33 \%$ and $25 \%$ of the $\mathrm{GeS}_{2}$ glass former, respectively, which are not sufficient to vitrify these melts on quenching.

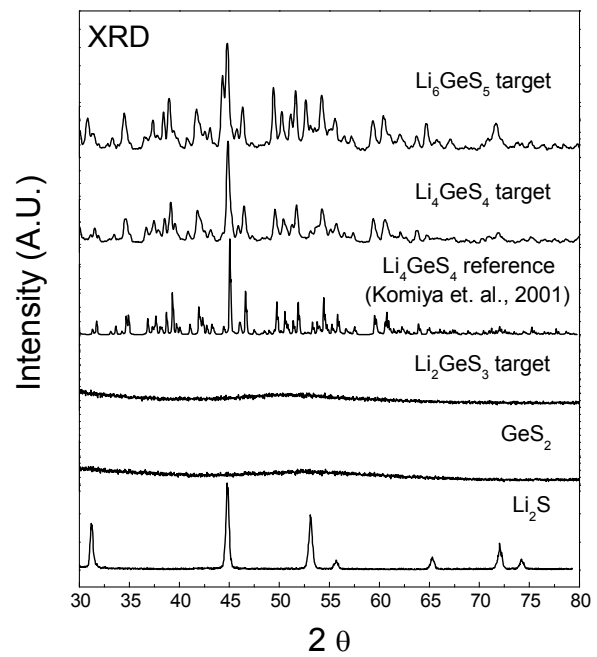

Fig. 3. XRD patterns of crystalline $\mathrm{Li}_{2} \mathrm{~S}, \mathrm{GeS}_{2}$ glass, and target materials

To verify the XRD pattern of the $\mathrm{Li}_{4} \mathrm{GeS}_{4}$ target material which was quenched on a brass plate in the glovebox, and the reference data(Komiya et al., 2001) of $\mathrm{Li}_{4} \mathrm{GeS}_{4}$ is also shown in Figure (3). The XRD pattern of our experimental $\mathrm{Li}_{4} \mathrm{GeS}_{4}$ target material shows slightly broader peaks than those of the reference data(Komiya et al., 2001). A possible reason is that the $\mathrm{Li}_{4} \mathrm{GeS}_{4}$ target was quenched more quickly on a brass plate. This rapid quenching presumably produces a more defective crystal structure than typical slow cooled or solid- 
state reaction prepared samples. However, the XRD pattern of the $\mathrm{Li}_{4} \mathrm{GeS}_{4}$ target material still appears to closely match the reported reference pattern. Murayama et al.(Murayama et al., 2002) reported that the structure of $\mathrm{Li}_{4} \mathrm{GeS}_{4}$ is related to that of $\gamma-\mathrm{Li}_{3} \mathrm{PO}_{4}$ and is comprised of hexagonal close-packed sulfide ions with germanium ions distributed over the tetrahedral sites. In this structure, the $\mathrm{Li}^{+}$ions are located in both octahedral and tetrahedral sites. Murayama et al.(Murayama et al., 2002) suggested that the distribution of $\mathrm{Li}^{+}$ions in the $\mathrm{LiS}_{4}$ tetrahedra, the interstitial tetrahedral sites, and the $\mathrm{LiS}_{6}$ octahedra sites forms conduction pathways in the crystal. For this reason, the $\mathrm{Li}_{4} \mathrm{GeS}_{4}$ material shows higher ionic conductivity than oxide materials.

While XRD data of $\mathrm{Li}_{4} \mathrm{GeS}_{4}$ do not show peaks related to those of $\mathrm{Li}_{2} \mathrm{~S}$, XRD data of $\mathrm{Li}_{6} \mathrm{GeS}_{5}$ show peaks related to those of $\mathrm{Li}_{2} \mathrm{~S}$. This suggests that the XRD pattern for $\mathrm{Li}_{6} \mathrm{GeS}_{5}$ agrees well with the expectation that it is composed of equi-molar mixture of $\mathrm{Li}_{4} \mathrm{GeS}_{4}$ and $\mathrm{Li}_{2} \mathrm{~S}$. The $\mathrm{Li}_{4} \mathrm{GeS}_{4}$ and $\mathrm{Li}_{6} \mathrm{GeS}_{5}$ targets are crystalline as shown in Figure (3). The fact can also be seen from the Raman spectra in Figure (4). The $\mathrm{Li}_{2} \mathrm{GeS}_{3}, \mathrm{Li}_{4} \mathrm{GeS}_{4}$, and $\mathrm{Li}_{6} \mathrm{GeS}_{5}$ thin-films were not characterized by XRD because our standard XRD system is not sensitive enough to examine such thin-films as are reported here.

\subsubsection{Raman spectroscopy}

Starting materials, $\mathrm{GeS}_{2}$ and $\mathrm{Li}_{2} \mathrm{~S}$, targets, and thin films were characterized by Raman spectroscopy in order to analyze their purity and to determine their chemical structure and are shown in Figure (4). In the Raman spectrum of $\mathrm{GeS}_{2}$, a strong main peak appears at $\sim 340$ $\mathrm{cm}^{-1}$ that agrees well with that of literature(Cernosek et al., 1997) and is assigned to the

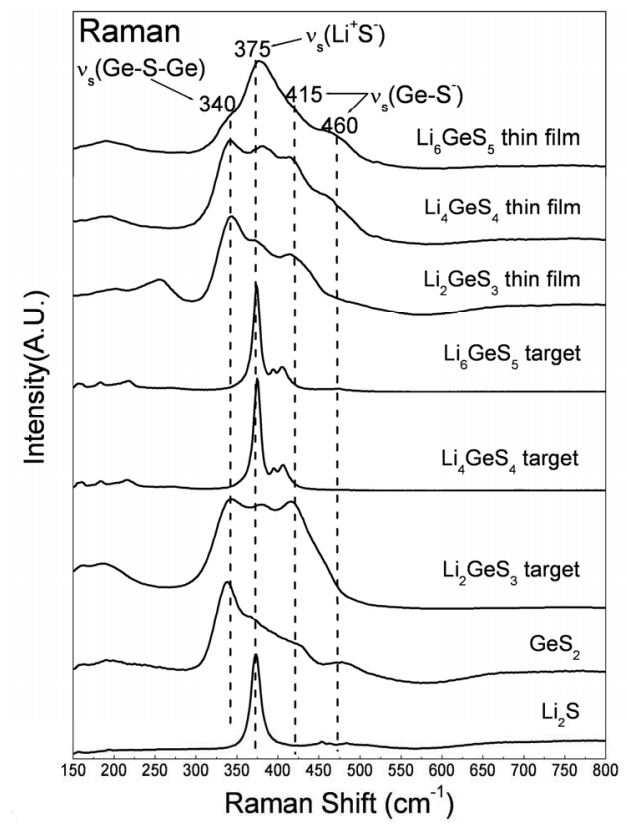

Fig. 4. Raman spectra of $\mathrm{Li}_{2} \mathrm{~S}, \mathrm{GeS}_{2}$, targets, and thin films. 
symmetric stretching of bridging sulfur, S (BS), (Ge-S-Ge) in the $\mathrm{GeS}_{4 / 2}$ tetrahedra. The Raman spectrum of $\mathrm{Li}_{2} \mathrm{~S}$ shows a single strong peak at $\sim 375 \mathrm{~cm}^{-1}$ which is assigned to $\mathrm{Li}^{+}-\mathrm{S}^{-}$ stretching modes. The Raman spectrum of the $\mathrm{Li}_{2} \mathrm{~S}$ is sharper than that of $\mathrm{GeS}_{2}$ glass because $\mathrm{Li}_{2} \mathrm{~S}$ is crystalline while the $\mathrm{GeS}_{2}$ is glassy.

In the spectrum of the $\mathrm{Li}_{2} \mathrm{GeS}_{3}$ target, there are three dominant peaks at 340, 375 and $415 \mathrm{~cm}^{-1}$. The peak at $340 \mathrm{~cm}^{-1}$ is found in $\mathrm{GeS}_{2}$ and is assigned to bridging sulfur (Ge-S-Ge) bonding. The peak at $375 \mathrm{~cm}^{-1}$ is found in the Raman spectrum of $\mathrm{Li}_{2} \mathrm{~S}$ and for this reason is assigned to $\mathrm{Li}^{+} \mathrm{S}-$ ionic bonding. The peak at $415 \mathrm{~cm}^{-1}$ is assigned to non-bridging sulfur (NBS) $\equiv$ Ge-S- ionic bonding. While there are three peaks in the Raman spectrum of $\mathrm{Li}_{2} \mathrm{GeS}_{3}$ target, the Raman spectra of the $\mathrm{Li}_{4} \mathrm{GeS}_{4}$ and $\mathrm{Li}_{6} \mathrm{GeS}_{5}$ targets show only one dominant peak at $375 \mathrm{~cm}^{-1}$. The strong main Raman peak in the both $\mathrm{Li}_{4} \mathrm{GeS}_{4}$ and $\mathrm{Li}_{6} \mathrm{GeS}_{5}$ target materials appears at $375 \mathrm{~cm}^{-1}$ which is at the same peak position of $\mathrm{Li}_{2} \mathrm{~S}$. This indicates that the $375 \mathrm{~cm}^{-1}$ peak in both of the target materials was related to that of the $\mathrm{Li}_{2} \mathrm{~S}$ component. The narrowing of the Raman peaks in spectra of $\mathrm{Li}_{6} \mathrm{GeS}_{5}$ and $\mathrm{Li}_{4} \mathrm{GeS}_{4}$ compounds compared to that of $\mathrm{Li}_{2} \mathrm{GeS}_{3}$ arises from the polycrystalline structure of the former compound and the glassy structure of the latter.

The Raman spectrum of the $\mathrm{Li}_{2} \mathrm{GeS}_{3}$ thin-film shows three dominant peaks at 340, 375, and $415 \mathrm{~cm}^{-1}$. The peak at $340 \mathrm{~cm}^{-1}$ coincindes with $\mathrm{GeS}_{2}$ main peak position and is assigned to the BS (Ge-S-Ge) mode. The $375 \mathrm{~cm}^{-1}$ peak is assigned to $\mathrm{Li}^{+}-\mathrm{S}^{-}$modes and the $415 \mathrm{~cm}^{-1}$ peak is assigned to NBS (Ge-S-) modes.

Among the three peaks, the peak at $340 \mathrm{~cm}^{-1}$ has the highest intensity. This is due to the high fractions $(50 \%)$ of $\mathrm{GeS}_{2}$ glass former in $\mathrm{Li}_{2} \mathrm{GeS}_{3}$. The Raman spectrum of the $\mathrm{Li}_{4} \mathrm{GeS}_{4}$ thinfilm also shows three peaks at 340, 375 and $415 \mathrm{~cm}^{-1}$, like the spectrum of the $\mathrm{Li}_{2} \mathrm{GeS}_{3}$ thinfilm, and another broader peak of lower intensity at $460 \mathrm{~cm}^{-1}$. The intensities of the peaks at 375 and $415 \mathrm{~cm}^{-1}$ are higher than those in the spectrum of the $\mathrm{Li}_{2} \mathrm{GeS}_{3}$ thin-film. This is consistent with the increased $\mathrm{Li}_{2} \mathrm{~S}$ content in the $\mathrm{Li}_{4} \mathrm{GeS}_{4}$ compared to $\mathrm{Li}_{2} \mathrm{GeS}_{3}$ which would increase the concentration of both $\mathrm{Li}^{+}{ }^{-}$and Ge-S- NBS modes. The Raman spectrum of the $\mathrm{Li}_{6} \mathrm{GeS}_{5}$ thin-film which has an even higher $\mathrm{Li}_{2} \mathrm{~S}$ content compared to the other thin-films only has one dominant peak at $375 \mathrm{~cm}^{-1}$ which is assigned to the $\mathrm{Li}^{+} \mathrm{S}-$ vibrational mode. This indicates that the $\mathrm{Li}_{6} \mathrm{GeS}_{5}$ thin-film contains the highest $\mathrm{Li}_{2} \mathrm{~S}$ content compared to the other two thin-films. There are three low intensity peaks at 340, 415 and $460 \mathrm{~cm}^{-1}$ in the spectrum of $\mathrm{Li}_{6} \mathrm{GeS}_{5}$. As described above, the peak at $340 \mathrm{~cm}^{-1}$ is assigned to the bridging sulfur (Ge-SGe bonding) and the peaks at 415 and $460 \mathrm{~cm}^{-1}$ are assigned to modes of the NBS (Ge-S-). The peak at $460 \mathrm{~cm}^{-1}$ is assigned to the $1 \mathrm{NBS}$ bonding and the peak is not present significantly in thin-films. The peak at $415 \mathrm{~cm}^{-1}$ is assigned to 2 NBS and the peak is present in thin-films. On the other hand, the peak at $340 \mathrm{~cm}^{-1}$ is assigned to $0 \mathrm{NBS}$ and the peak is present in thin-films. The Raman spectra of all other thin-films do not show sharp peaks, but rather show broad peaks compared to those of crystalline targets $\left(\mathrm{Li}_{4} \mathrm{GeS}_{4}\right.$ and $\left.\mathrm{Li}_{6} \mathrm{GeS}_{5}\right)$ and are consistent with the films being amorphous. As the $\mathrm{Li}_{2} \mathrm{~S}$ content increases in the targets $\left(\mathrm{Li}_{2}, \mathrm{Li}_{4}\right.$, and $\left.\mathrm{Li}_{6}\right)$, the $\mathrm{Li}_{2} \mathrm{~S}$ content in the thin-film increases. It can be concluded that although the previous reported literature showed $\mathrm{Li}_{2} \mathrm{~S}$ deficiency in $\mathrm{GeS}_{2}$-based thin-films after sputtering compared to that of target,(Yamashita et al., 1996a) the amount of $\mathrm{Li}_{2} \mathrm{~S}$ in the thin-films in this study increases with the increase of $\mathrm{Li}_{2} \mathrm{~S}$ in the target and are consistent with the $\mathrm{Li}_{2} \mathrm{~S}$ content in the targets. 


\subsubsection{Infrared (IR) spectroscopy}

To further characterize the starting materials, $\mathrm{Li}_{2} \mathrm{~S}$ crystalline powder and $\mathrm{GeS}_{2}$ glass powder, targets, and their thin-films were characterized by infrared spectroscopy. Attention is focused on the far-IR region ( 900 to $100 \mathrm{~cm}^{-1}$ ) in order to evaluate the nature of the chemical bonding in the materials, as well as the mid-IR region (4000 to $\left.400 \mathrm{~cm}^{-1}\right)$ in order to determine how these materials might be contaminated by oxygen and/or moisture before and/or after processing. However, due to the lack of any significant $\mathrm{O}$ or $\mathrm{OH}$ contamination in the films and the very thin dimension observed, the mid-IR spectra are not shown here. However, in the far-IR region, strong absorptions were observed and arise from the framework structure species $\mathrm{Li}, \mathrm{Ge}$, and $\mathrm{S}$.

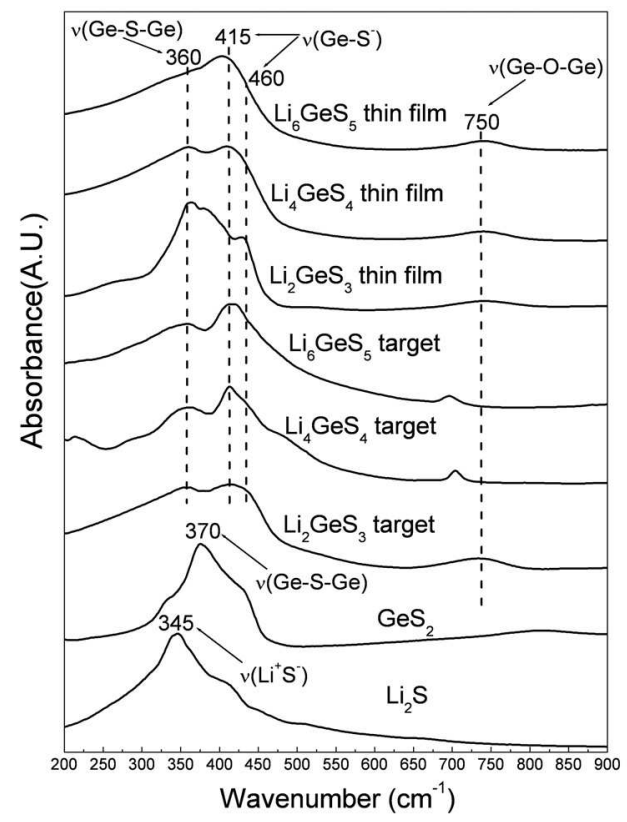

Fig. 5. Infrared spectra of $\mathrm{Li}_{2} \mathrm{~S}, \mathrm{GeS}_{2}$, targets, and thin-films

The IR spectra of polycrystalline $\mathrm{Li}_{2} \mathrm{~S}$, glassy $\mathrm{GeS}_{2}$, targets and thin films are shown in Figure (5). The IR peak in the far-IR spectrum of $\mathrm{Li}_{2} \mathrm{~S}$ at $\sim 345 \mathrm{~cm}^{-1}$ is assigned to the ionic bonding of $\mathrm{Li}^{+} S^{-}$and the strong peak at $\sim 370 \mathrm{~cm}^{-1}$ in the spectrum of glassy $\mathrm{GeS}_{2}$ is assigned to the BS, $v(\mathrm{Ge}-\mathrm{S}-\mathrm{Ge}, \mathrm{BS})$ mode of the $\mathrm{GeS}_{4 / 2}$ tetrahedra.(Zhou et al., 1999) It is possible that the broad peak in the IR spectrum of $\mathrm{GeS}_{2}$ can be deconvoluted into two additional peaks, one centered at $\sim 325 \mathrm{~cm}^{-1}$ and the other centered at $\sim 435 \mathrm{~cm}^{-1}$. These two additional peaks also arise from vibrational modes of the $\mathrm{GeS}_{4 / 2}$ tetrahedra. (Frumarova et al., 1996) The shift in wavenumbers can be due to the presence of compressive stress in the film which is expected for films deposited by RF sputtering. In the IR spectra of the $\mathrm{GeS}_{2}$, there is one broad and low intensity peak at $\sim 800 \mathrm{~cm}^{-1}$. (Zhou et al., 1999) This peak is assigned to the preparation and handling giving rise to a $\mathrm{Ge}-\mathrm{O}$ bonding mode. It can be assumed that $\mathrm{GeS}_{2}$ might be slightly contaminated by oxygen during IR sample measurement. In the IR spectra 
of both the starting materials, there is no peak at $\sim 1500 \mathrm{~cm}^{-1}(\mathrm{O}-\mathrm{H}$ vibration mode) or at $\sim 3500 \mathrm{~cm}^{-1}$ (O-H stretching mode) so this suggests that these two starting materials are not significantly contaminated by oxygen or moisture.

The IR spectra of $\mathrm{Li}_{2} \mathrm{GeS}_{3}, \mathrm{Li}_{4} \mathrm{GeS}_{4}$ and $\mathrm{Li}_{6} \mathrm{GeS}_{4}$ targets show dominant peaks at $\sim 360 \mathrm{~cm}^{-1}$ and $415 \mathrm{~cm}^{-1}$ and a low intensity peak at $\sim 750 \mathrm{~cm}^{-1}$. The IR peak at $\sim 360 \mathrm{~cm}^{-1}$ is assigned to the BS, v(Ge-S-Ge, BS) mode and the $415 \mathrm{~cm}^{-1}$ peak corresponds to the vibration stretch of Ge with two non-bridging sulfur atoms. The broad IR peak at $\sim 360 \mathrm{~cm}^{-1}$ can be deconvoluted into two peaks one centered at $345 \mathrm{~cm}^{-1}$ corresponding to $\mathrm{Li}^{+} \mathrm{S}$ - mode and the other centered at $\sim 360 \mathrm{~cm}^{-1}$ corresponding to Ge-S-Ge mode. In addition, one low intensity peak which is assigned to oxide impurities, $v$ (Ge-O-Ge) appears at $\sim 750 \mathrm{~cm}^{-1}$. It is possible that contamination occurs when the target materials are melted in the glovebox because a background level of several ppm $\mathrm{O}_{2}$ exists in the glovebox. Another possibility is that the oxygen comes from the $\mathrm{GeS}_{2}$, its spectrum in Figure (6) shows that there is a low intensity peak at $\sim 750 \mathrm{~cm}^{-1}$ assigned to $\mathrm{GeO}_{2}$.

To the best of our knowledge, the IR spectra of the thio-germanate based thin-film materials have not been reported in the open literature. In this research, in order to characterize the thin-films by IR spectroscopy, the $\mathrm{Li}_{2} \mathrm{GeS}_{3}, \mathrm{Li}_{4} \mathrm{GeS}_{4}$ and $\mathrm{Li}_{6} \mathrm{GeS}_{5}$ thin-films were deposited directly on the top side of pressed CsI pellets that provided a mid- and far-IR transparent support for the films. The $\mathrm{Li}_{2} \mathrm{GeS}_{3}, \mathrm{Li}_{4} \mathrm{GeS}_{4}$ and $\mathrm{Li}_{6} \mathrm{GeS}_{5}$ thin-films were deposited directly on the pressed CsI pellets and the IR spectra were then collected in transmission. The intense peak at $\sim 360 \mathrm{~cm}^{-1}$ can be deconvoluted into two peaks one centered at $345 \mathrm{~cm}^{-1}$ corresponding to the $\mathrm{Li}^{+} \mathrm{S}-$ mode and the other centered at $\sim 360 \mathrm{~cm}^{-1}$ corresponding to the Ge-S-Ge mode as described above and the intensity of this peak decreases with added $\mathrm{Li}_{2} \mathrm{~S}$. In addition, one low intensity peak which is assigned to oxide impurities, v(Ge-O-Ge) appears at $\sim 750 \mathrm{~cm}^{-1}$. A new band appears at $445 \mathrm{~cm}^{-1}$ as a result of the formation of nonbridging sulfurs -Ge-S--Li+ (NBS). This NBS band was reported at $\sim 450 \mathrm{~cm}^{-1}$ in the IR spectra of binary $\mathrm{xNa}_{2} \mathrm{~S}+(1-\mathrm{x}) \mathrm{GeS}_{2}$ glasses.(Barrau et al., 1980) The NBS band at $445 \mathrm{~cm}^{-1}$ diminishes as another NBS band at $415 \mathrm{~cm}^{-1}$ grows stronger with further additions of $\mathrm{Li}_{2} \mathrm{~S}$ and this suggests that the number of NBS per Ge increases with the addition of $\mathrm{Li}_{2} \mathrm{~S}$. Indeed, it is expected from the compositions that these would be two NBS in $\mathrm{Li}_{2} \mathrm{GeS}_{3}$ and four NBS in $\mathrm{Li}_{4} \mathrm{GeS}_{4}$ and $\mathrm{Li}_{6} \mathrm{GeS}_{5}$.

\subsubsection{Surface morphology and thickness of the thin-film}

In order to determine the sputtering rate, the thickness of the thin-films were measured in the cross-section direction by FE-SEM as shown in Figure (6-a). A Ni adhesion layer $(\sim 120 \mathrm{~nm})$ is used to improve the adhesion between the Si wafer and the thin-film. The Ni adhesion layer is also very useful for Raman spectroscopy. In particular, when one characterizes the films using micro-Raman spectroscopy, the dominant silicon peak, $\sim 520 \mathrm{~cm}^{-1}$, appears in Raman spectra unless a barrier layer is used. Therefore, the Ni adhesion layer also acted to prevent the appearance of the peak from the silicon substrate. Furthermore, it has been found that $\mathrm{Ni}$ is chemically stable in contact with the lithium thio-germanate thin-film electrolytes.(Bourderau et al., 1999) The sputtering power and pressure of $50 \mathrm{~W}$ and 25 mtorr $(\sim 3.3 \mathrm{~Pa})$ were used, respectively, and the total thickness of the thin- film after two hours of sputtering was $\sim 1.3 \mu \mathrm{m}$ which gives a sputtering rate of $\sim 5 \mathrm{~nm} /$ minute. 


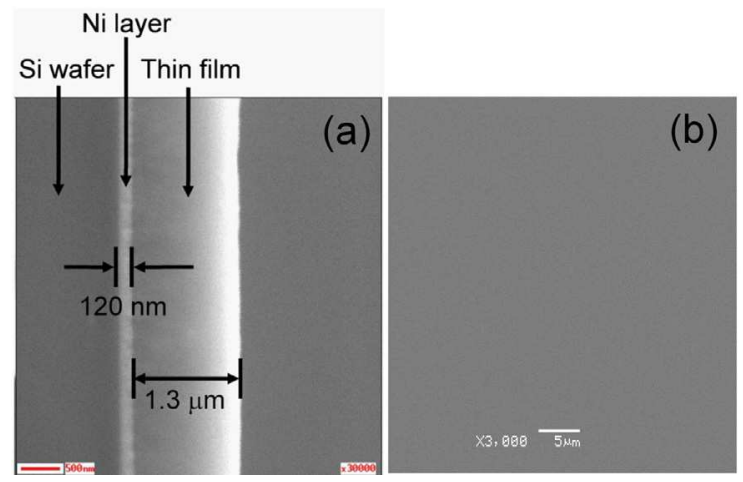

Fig. 6. FE-SEM images of cross-sectional view (a) and top view (b) of $\mathrm{Li}_{4} \mathrm{GeS}_{4}$ thin film grown on a Ni/Si substrate in an Ar atmosphere.

Figure (6-b) shows the surface morphology of the thin-films produced in an Ar atmosphere. The thin-film surface is mirror-like without any defects or cracks. This suggests that the thin-film electrolytes are homogeneous and have a flat surface morphology. The smooth surface enables the thin-films to decrease the contact resistance between thin-film and the electrodes.

\subsubsection{Impedance analysis}

In order to measure the ionic conductivity of the thin-films, they were deposited on a single crystal $\mathrm{Al}_{2} \mathrm{O}_{3}$ substrate. The sapphire substrates were loaded into a d.c. sputtering chamber in the glovebox and covered by the stainless steel mask with two $2 \mathrm{~mm} \times 10 \mathrm{~mm}$ slits at 2 $\mathrm{mm}$ apart parallel to each other to produce two $2 \mathrm{~mm} \times 10 \mathrm{~mm}$ parallel electrodes $2 \mathrm{~mm}$ apart on the sapphire substrate. Au electrodes of $\sim 100 \mathrm{~nm}$ thickness were sputtered for 20 min. at a sputtering rate of $5 \mathrm{~nm} / \mathrm{min}$. through the mask. Lastly, the substrate then was loaded into the RF magnetron sputtering chamber to grow the thin-film electrolytes.

The conductivities of the thin-films were determined from the resulting complex impedance spectra. The semicircle at high frequency represents the response of the thin-film materials to an applied electric field. Thus, the d.c. resistance can be calculated from the semicircle plot. The ionic conductivities of the thin-films can be calculated from the measured d.c. resistance, $\mathrm{R}$, the thickness of the electrolyte $t$, its area $\mathrm{A}$, and $t / \mathrm{A}$ is the cell constant.

The ionic conductivities of the $\mathrm{Li}_{6} \mathrm{GeS}_{5}$ thin-film grown in $\mathrm{Ar}$ atmosphere at various temperatures from $-25{ }^{\circ} \mathrm{C}$ to $100{ }^{\circ} \mathrm{C}$ with $25{ }^{\circ} \mathrm{C}$ increments are shown in Figure (7). The ionic conductivities of the $\mathrm{Li}_{6} \mathrm{GeS}_{5}$ thin-film in $\mathrm{Ar}$ atmosphere at $25{ }^{\circ} \mathrm{C}$ and at $100{ }^{\circ} \mathrm{C}$ are $1.7 \times 10^{-3} \mathrm{~S} / \mathrm{cm}$ and $3.0 \times 10^{-2} \mathrm{~S} / \mathrm{cm}$, respectively. As the temperature increases from $-25{ }^{\circ} \mathrm{C}$ to $100{ }^{\circ} \mathrm{C}$, the ionic conductivity continually increased and was found to be stable over this temperature range. This thin-film appears to be stable wider temperature range compared to liquid electrolytes (Guyomard and Tarascon, 1995).

Figure (8) shows a Nyquist plot of the complex impedance for the $\mathrm{Li}_{6} \mathrm{GeS}_{5}$ thin-film grown in an $\mathrm{Ar}$ atmosphere over the temperature ranges from $25^{\circ} \mathrm{C}$ to $100{ }^{\circ} \mathrm{C}$ with $25^{\circ} \mathrm{C}$ increments. 
The frequency increases for each point from right to left starting at $0.1 \mathrm{~Hz}$ and finishing at 1 $\mathrm{MHz}$. The spike at low frequencies represents polarization of the $\mathrm{Li}$ ions due to the use of $\mathrm{Au}$ blocking electrodes. The d.c resistance can be calculated from the semicircle as shown in Figure (8).

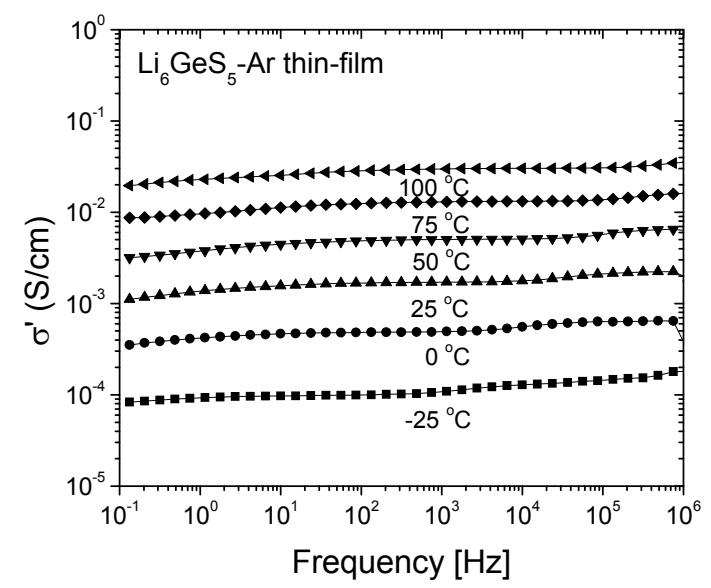

Fig. 7. The ionic conductivity of $\mathrm{Li}_{6} \mathrm{GeS}_{5}$ thin-film grown in Ar atmospheres over the temperatures from $-25^{\circ} \mathrm{C}$ to $100{ }^{\circ} \mathrm{C}$ with $25^{\circ} \mathrm{C}$ increments.

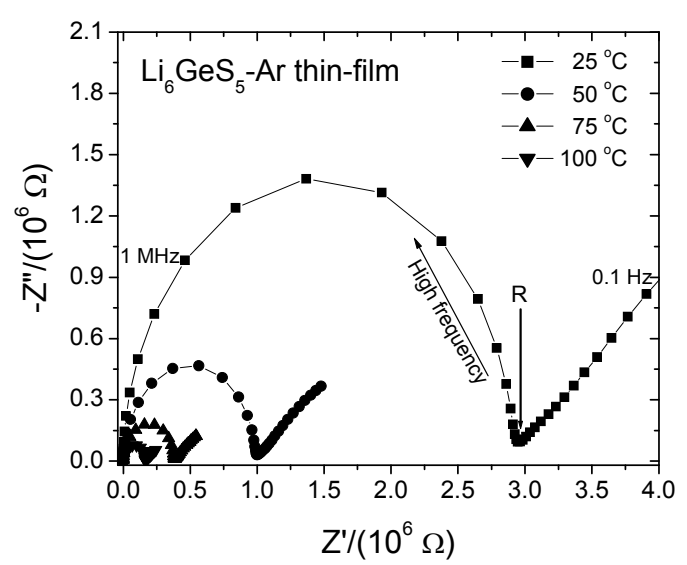

Fig. 8. Nyquist plot of the complex impedance for the $\mathrm{Li}_{6} \mathrm{GeS}_{5}$ thin-film in Ar atmosphere over the various temperatures from $25^{\circ} \mathrm{C}$ to $100{ }^{\circ} \mathrm{C}$.

The ionic conductivities were calculated from the resistance and cell constant relations and are listed in Table (1). The d.c. ionic conductivities of the $\mathrm{Li}_{2} \mathrm{GeS}_{3}, \mathrm{Li}_{4} \mathrm{GeS}_{4}, \mathrm{Li}_{6} \mathrm{GeS}_{5}$ and $\mathrm{Li}_{8} \mathrm{GeS}_{6}$ thin-films are also shown in Table (1). The ionic conductivities of all four thin-films were characterized with the same temperature ranges, from $-25{ }^{\circ} \mathrm{C}$ to $100{ }^{\circ} \mathrm{C}$ with $25{ }^{\circ} \mathrm{C}$ increments, and same frequency ranges, from $0.1 \mathrm{~Hz}$ to $1 \mathrm{MHz}$. As shown in Table 1, the ionic conductivities of the $\mathrm{Li}_{4} \mathrm{GeS}_{4}$ thin-film are higher than those of $\mathrm{Li}_{2} \mathrm{GeS}_{3}$ thin-film at each temperature. The reason for the $\mathrm{Li}_{4} \mathrm{GeS}_{4}$ thin-film having a higher ionic conductivity 
than the $\mathrm{Li}_{2} \mathrm{GeS}_{3}$ thin-film is that the $\mathrm{Li}_{4} \mathrm{GeS}_{4}$ thin-film contains a higher $\mathrm{Li}_{2} \mathrm{~S}$ content. The ionic conductivities at room temperature and $100{ }^{\circ} \mathrm{C}$ of the $\mathrm{Li}_{4} \mathrm{GeS}_{4}$ thin-film are $7.5 \times 10^{-4} \mathrm{~S} / \mathrm{cm}$ and $1.3 \times 10^{-2} \mathrm{~S} / \mathrm{cm}$, respectively. As the temperature increased, the ionic conductivities increase without decreasing and hence the thin-films are stable over wide temperature ranges.

\begin{tabular}{ccccc}
\hline Temp. & $\begin{array}{c}\mathrm{Li}_{2} \mathrm{GeS}_{3} \\
(\mathrm{~S} / \mathrm{cm})\end{array}$ & $\begin{array}{c}\mathrm{Li}_{4} \mathrm{GeS}_{4} \\
(\mathrm{~S} / \mathrm{cm})\end{array}$ & $\begin{array}{c}\mathrm{Li}_{6} \mathrm{GeS}_{5} \\
(\mathrm{~S} / \mathrm{cm})\end{array}$ & $\begin{array}{c}\mathrm{Li}_{8} \mathrm{GeS}_{6} \\
(\mathrm{~S} / \mathrm{cm})\end{array}$ \\
\hline$-25^{\circ} \mathrm{C}$ & $4.0 \times 10^{-6}$ & $4.6 \times 10^{-5}$ & $9.7 \times 10^{-5}$ & $2.6 \times 10^{-6}$ \\
$0{ }^{\circ} \mathrm{C}$ & $2.5 \times 10^{-5}$ & $2.2 \times 10^{-4}$ & $4.8 \times 10^{-4}$ & $1.5 \times 10^{-5}$ \\
$25^{\circ} \mathrm{C}$ & $1.1 \times 10^{-4}$ & $7.5 \times 10^{-4}$ & $1.7 \times 10^{-3}$ & $7.3 \times 10^{-5}$ \\
$50^{\circ} \mathrm{C}$ & $3.8 \times 10^{-4}$ & $2.2 \times 10^{-3}$ & $5.0 \times 10^{-3}$ & $1.9 \times 10^{-4}$ \\
$75^{\circ} \mathrm{C}$ & $1.1 \times 10^{-3}$ & $5.8 \times 10^{-3}$ & $1.3 \times 10^{-2}$ & $5.7 \times 10^{-4}$ \\
$100^{\circ} \mathrm{C}$ & $2.9 \times 10^{-3}$ & $1.3 \times 10^{-2}$ & $3.0 \times 10^{-2}$ & $1.4 \times 10^{-3}$ \\
\hline
\end{tabular}

Table 1. D.c. ionic conductivities over the temperatures from $-25{ }^{\circ} \mathrm{C}$ to $100{ }^{\circ} \mathrm{C}$ at $25^{\circ} \mathrm{C}$ increments for $\mathrm{nLi}_{2} \mathrm{~S}+\mathrm{GeS}_{2}, \mathrm{n}=1,2,3$, and 4, thin-films grown in Ar atmosphere

The ionic conductivities of the $\mathrm{Li}_{6} \mathrm{GeS}_{5}$ thin-film at room temperature and $100{ }^{\circ} \mathrm{C}$ are $1.7 \times 10^{-3} \mathrm{~S} / \mathrm{cm}$ and $3.0 \times 10^{-2} \mathrm{~S} / \mathrm{cm}$, respectively. The ionic conductivities of the $\mathrm{Li}_{6} \mathrm{GeS}_{5}$ thin-film increase with increasing temperatures. As $n$ increases in $\mathrm{nLi}_{2} \mathrm{~S}+\mathrm{GeS}_{2}$ from 1 to 3 , the ionic conductivities increase at all temperatures. For the $n=3$ thin-films, the ionic conductivity was measured to be $>10^{-3} \mathrm{~S} / \mathrm{cm}$ at $25{ }^{\circ} \mathrm{C}$ which is very high compared to the ionic conductivity of oxide thin-films which are $\sim 10^{-6} \mathrm{~S} / \mathrm{cm}$ at $25^{\circ} \mathrm{C}$.

To determine if a maximum $\mathrm{Li}^{+}$ionic conductivity occurs for this series of materials, a $\mathrm{Li}_{8} \mathrm{GeS}_{6}$ thin-film, $\mathrm{n}=4$ in $\mathrm{nLi}_{2} \mathrm{~S}+\mathrm{GeS}_{2}$, was prepared and the ionic conductivities were analyzed over the same temperature and frequency ranges. The ionic conductivities of the $\mathrm{Li}_{8} \mathrm{GeS}_{6}$ thin-film at $25^{\circ} \mathrm{C}$ and $100{ }^{\circ} \mathrm{C}$ are $7.3 \times 10^{-5} \mathrm{~S} / \mathrm{cm}$ and $1.4 \times 10^{-3} \mathrm{~S} / \mathrm{cm}$, respectively. While the d.c. ionic conductivities of the thin-films from $n=1$ to 3 in $\mathrm{nLi}_{2} \mathrm{~S}+\mathrm{GeS}_{2}$ increased with $n$, the d.c. ionic conductivity of the thin-film for $n=4, \mathrm{Li}_{8} \mathrm{GeS}_{6}$, decreased and this is caused by the activation energy increasing, see discussion below.

In this series of films, the $\mathrm{n}=3$ composition, $\mathrm{Li}_{6} \mathrm{GeS}_{5}$, is the optimized composition with the highest ionic conductivity in the $\mathrm{nLi}_{2} \mathrm{~S}+\mathrm{GeS}_{2}$ system, $\mathrm{n}=1,2,3$, and 4 . Although the $\mathrm{n}=4$ composition, $\mathrm{Li}_{8} \mathrm{GeS}_{6}$, thin-film showed lower ionic conductivities than those of the $\mathrm{n}=1\left(\mathrm{Li}_{2} \mathrm{GeS}_{3}\right), 2\left(\mathrm{Li}_{4} \mathrm{GeS}_{4}\right)$, and $3\left(\mathrm{Li}_{6} \mathrm{GeS}_{5}\right)$ compositions, the ionic conductivities of all four of these thin-films are significantly higher than that of LiPON. In addition, all compositions $\mathrm{n}=1,2,3$, and 4 of the sulfide thin-film electrolytes are very stable over wide temperature ranges compared to liquid or polymer electrolytes. Therefore, Li-ion batteries using these sulfide thin-film electrolytes are promising for use in solid-state lithium-ion batteries.

For all thin-films, the ionic conductivities were found to follow an Arrhenius law, $\sigma_{\text {d.c. }}$ $(T)=\sigma_{o} \exp \left(-\Delta E_{a} / R T\right)$, over the measured temperature ranges. The Arrhenius plots of the d.c. ionic conductivities of the thin-films over the temperature range from $-25{ }^{\circ} \mathrm{C}$ to $100{ }^{\circ} \mathrm{C}$ with $25{ }^{\circ} \mathrm{C}$ increments are shown in Figure (9) and are compared to that of LiPON. The 
activation energies of conduction, $\Delta \mathrm{E}_{\mathrm{a}}$, were calculated from the slope of the Arrhenius plots. The ionic conductivities of the thin-films at room temperature, the activation energies, and pre-exponential factors are listed in Table (2).

The ionic conductivities of the all-sulfide thin-films higher than that of $\operatorname{LiPON}(\mathrm{Yu}$ et al., 1997). In the case of the $\mathrm{Li}_{6} \mathrm{GeS}_{5}$ thin-film, the ionic conductivity at $25{ }^{\circ} \mathrm{C}$ is approximately three orders of magnitude higher than that of $\mathrm{LiPON}(\mathrm{Yu}$ et al., 1997). The composition dependence of the ionic conductivities of all thin-films, $n=1,2,3$, and 4 in $\mathrm{nLi}_{2} \mathrm{~S}+\mathrm{GeS}_{2}$ system, at $25{ }^{\circ} \mathrm{C}$ and their activation energies are shown in Figure (10) to show how they depend upon $\mathrm{Li}_{2} \mathrm{~S}$ content. The thin-films showed that as $\mathrm{Li}_{2} \mathrm{~S}$ content increases, the ionic conductivities increase up to $\mathrm{n}=3,75 \% \mathrm{Li}_{2} \mathrm{~S}$.

In addition, while the conductivity of the bulk sulfide glasses are less than that of the thinfilms, the ionic conductivities of the sulfide bulk glasses(Kim et al., 2006) over the range from $35 \%$ to $50 \%$ the ionic conductivities also increased. It is significant to note that the ionic conductivity decreased and the activation energies increased for the thin-films at $n=4$.

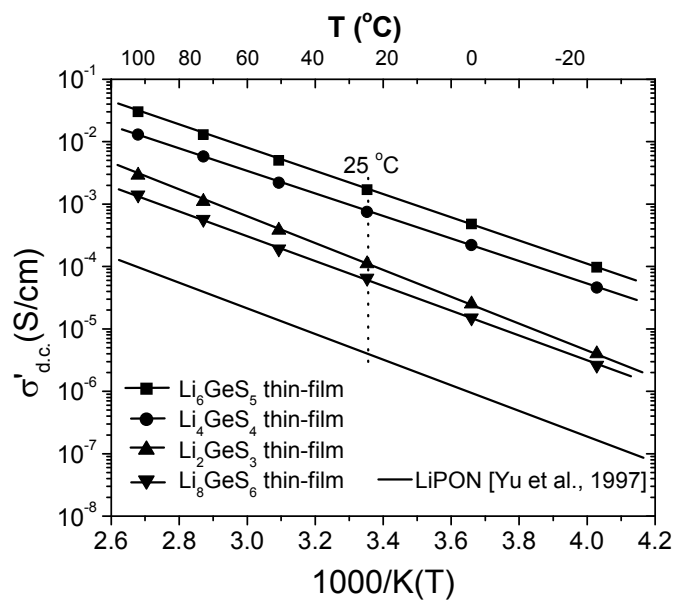

Fig. 9. Arrhenius plot of the ionic conductivities at various temperatures for $\mathrm{Li}_{2} \mathrm{GeS}_{3}$, $\mathrm{Li}_{4} \mathrm{GeS}_{4}, \mathrm{Li}_{6} \mathrm{GeS}_{5}$, and $\mathrm{Li}_{8} \mathrm{GeS}_{6}$ thin-films in Ar atmosphere and comparison of ionic conductivities between thin-films and LiPON (Yu et al., 1997).

\begin{tabular}{cccc}
\hline Composition & $\sigma_{25^{\circ} \mathrm{C}}(\mathrm{S} / \mathrm{cm})$ & $\begin{array}{c}\Delta \mathrm{E}_{\mathrm{a}}(\mathrm{kJ} / \mathrm{mol}) \\
( \pm 0.05)\end{array}$ & $\begin{array}{c}\log _{10}\left[\sigma_{\mathrm{o}}(\mathrm{S} / \mathrm{cm})\right] \\
( \pm 0.005)\end{array}$ \\
\hline $\mathrm{Li}_{2} \mathrm{GeS}_{3}$-Ar thin-film & $1.1( \pm 0.05) \times 10^{-4}$ & 40.2 & 3.096 \\
\hline $\mathrm{Li}_{4} \mathrm{GeS}_{4}-\mathrm{Ar}$ thin-film & $7.5( \pm 0.05) \times 10^{-4}$ & 34.5 & 2.951 \\
\hline $\mathrm{Li}_{6} \mathrm{GeS}_{5}-$ Ar thin-film & $1.7( \pm 0.05) \times 10^{-3}$ & 35.0 & 3.382 \\
\hline $\mathrm{Li}_{8} \mathrm{GeS}_{6}-$ Ar thin-film & $7.0( \pm 0.05) \times 10^{-5}$ & 38.1 & 2.763 \\
\hline
\end{tabular}

Table 2. Ionic conductivities at room temperature and activation energies for $\mathrm{nLi}_{2} \mathrm{~S}+\mathrm{GeS}_{2}$ ( $\mathrm{n}=1,2,3$, and 4$)$ thin-films in Ar atmosphere 
Further, the effective basicity of the counter and charge compensating anion in the structure of these materials is also expected to change significantly with $n$. In the $n=1,2,3$, and 4 films, the structure is expected to consist of increasing numbers of sulfurs possessing a single negative charge, and recent XPS studies of these same films show that these films are comprised of the nominal structures shown in Figure (11). In these structures, the average charge on the sulfur is expected to change from $-2 / 3,-4 / 4,-6 / 5$ to $-8 / 6$. At $\mathrm{Li}_{2} \mathrm{~S}$, the formal charge of the sulfur is expected to $-2 / 1$. Hence, while increasing the number of $\mathrm{Li}^{+}$is important to increasing the ionic conductivity, the negative charge density on the sulfur increases by a factor of 2 in this series and as a result the columbic binding energy of these increasingly basic sulfurs will increase as well. It appears that for the $n=3$ composition, the larger number of $\mathrm{Li}$ is still important because the appearance of the full $-2 / 1$ negatively charged $\mathrm{Li}_{2} \mathrm{~S}$ unit does increase the conductivity activation energy, $35 \mathrm{~kJ} / \mathrm{mol}$ for $\mathrm{n}=3$ versus $34.5 \mathrm{~kJ} / \mathrm{mol}$ for $\mathrm{n}=2$, but the conductivity is still higher, presumably because of the composition (n) dependence of the pre-exponential factor.

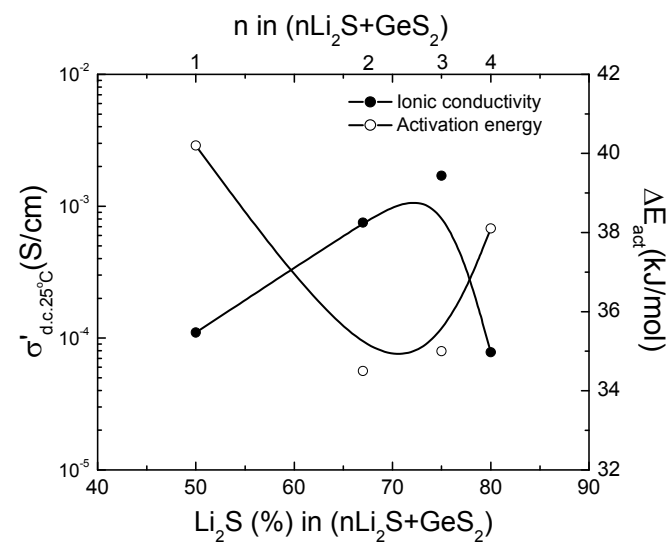

Fig. 10. Ionic conductivities and activation energies of the thin films $n=1,2,3$, and 4 in $\mathrm{nLi}_{2} \mathrm{~S}+\mathrm{GeS}_{2}$ system at $25^{\circ} \mathrm{C}$.

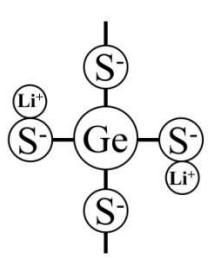

(b) $\mathrm{Li}_{2} \mathrm{GeS}_{3}$

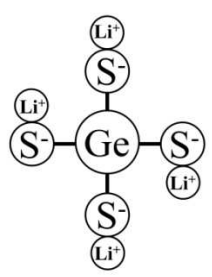

(c) $\mathrm{Li}_{4} \mathrm{GeS}_{4}$

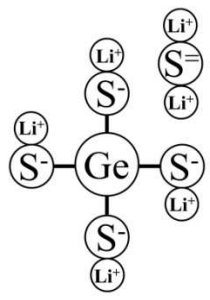

(d) $\mathrm{Li}_{6} \mathrm{GeS}_{5}$

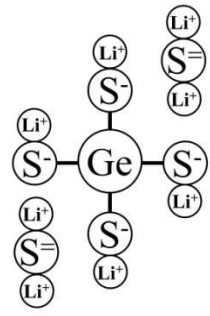

(a) $\mathrm{Li}_{8} \mathrm{GeS}_{6}$

Fig. 11. Atomic structure of the four nominal compositions with $n(n=1,2,3$, and 4).

We have shown in our other studies of these thin-films that the fraction of NBS Ge-Sincreases with $\mathrm{n}$ in these series. For $\mathrm{n}=1$, the fraction of bridging sulfurs S-Ge-S and nonbridging sulfurs Ge-S- are $1 / 3$ and 2/3, respectively. At $n=2$, these fractions are 0 and 1 , 
respectively. For $n=3$ and $n=4$, these units are expected to be connected to non-bridging sulfur units and new $S=$ units. Hence, the fraction of sulfur in non-bridging Ge-S- units and

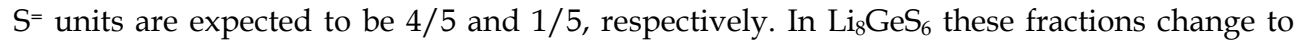
$4 / 6$ and $2 / 6$, respectively. The increase in the fraction of $\mathrm{Li}^{+}$ions bound to $\mathrm{S}=$ units increases from 0 for $\mathrm{Li}_{2} \mathrm{GeS}_{3}$ and $\mathrm{Li}_{4} \mathrm{GeS}_{4}$ to $2 / 6$ (33\%) and 4/8 (50\%) for $\mathrm{Li}_{6} \mathrm{GeS}_{5}$ and $\mathrm{Li}_{8} \mathrm{GeS}_{6}$, respectively. Due to the high binding energy expected for $\mathrm{Li}^{+}$ions about these $\mathrm{S}=$ ions it is therefore not surprising to see that the activation energy passes through a minimum at the $\mathrm{n}$ $=2$ composition and increases for $\mathrm{n}=3$ and 4 . Such a maximum in conductivity and minimum activation energy have been observed in other high alkali glass forming system where the anionic basicity of the host network increases significantly in the high alkali modifier range(Martin and Angell, 1984).

\subsubsection{X-ray photoelectron spectroscopy (XPS) analysis}

\subsubsection{Analysis of the $\mathrm{Li}_{2} \mathrm{~S}$ and $\mathrm{GeS}_{2}$ starting materials}

In order to verify the purity of the starting materials, the $\mathrm{Li}_{2} \mathrm{~S}$ and $\mathrm{GeS}_{2}$ were examined by XPS. In the case of the commercially purchased $\mathrm{Li}_{2} \mathrm{~S}$ material, Table (3) shows that the concentration of $\mathrm{C}$ and $\mathrm{O}$ were $\sim 12 \%$ and $\sim 21 \%( \pm 3 \%)$, respectively, and as such relatively high.

\begin{tabular}{ccccccc}
\hline At $\%$ & Li1s & Ge2p3 & S2p & C1s & O1s & Comments \\
\hline \multirow{2}{*}{$\mathrm{Li}_{2} \mathrm{~S}$} & 44.7 & - & 22.9 & 11.7 & 20.7 & As-prepared \\
& 66.1 & - & 33.9 & - & - & Ignoring C and O \\
& 66.7 & - & 33.3 & 0.0 & 0.0 & Expected values \\
\hline \multirow{2}{*}{$\mathrm{GeS}_{2}$} & - & 34.2 & 59.2 & 6.6 & 0.0 & As-prepared \\
& - & 35.7 & 64.3 & - & 0.0 & Ignoring C \\
\hline
\end{tabular}

Table 3. XPS compositional analysis of the $\mathrm{Li}_{2} \mathrm{~S}$ and $\mathrm{GeS}_{2}$ starting materials.

One possibility is that the $\mathrm{Li}_{2} \mathrm{~S}$ was slightly contaminated on the surface in the glovebox because the glovebox contained several ppm level of oxygen. Another possible reason for this can also include the "see-through" effect due to the double-sided tape used to adhere the powder to the XPS sample holder. The ratio of $\mathrm{Li}$ to $\mathrm{S}$, however, $1.95: 1.00$ is very close to the expected value of $2: 1$.

From Table (3), while the $\mathrm{Li}_{2} \mathrm{~S}$ shows relatively high $\mathrm{O}$ content, the $\mathrm{GeS}_{2}$ material was not contaminated by oxygen due in part to the fact that $\mathrm{GeS}_{2}$ material is less hygroscopic than other sulfide materials, but also due to the fact that this material was prepared from high purity starting materials, Ge and S (99.9999\%), in the very controlled conditions of our laboratory. $\mathrm{GeS}_{2}$ contains a small percent of $\mathrm{C}$, presumably surface $\mathrm{C}$, see Table (3), and after ignoring $\mathrm{C}$, the compositional data of $\mathrm{GeS}_{2}$ agrees well with expected values.

Deconvoluted S2p core XPS spectra for crystalline $\mathrm{Li}_{2} \mathrm{~S}$ (a) and glassy $\mathrm{GeS}_{2}$ (b) starting materials are shown in Figure (12). The binding energies for sulfur in $\mathrm{Li}_{2} \mathrm{~S}$ and $\mathrm{GeS}_{2}$ are at 
$160.7 \mathrm{eV}$ and $163.2 \mathrm{eV} \pm 0.2 \mathrm{eV}$, respectively. The reason for the difference in the S2p binding energies between $\mathrm{Li}_{2} \mathrm{~S}$ and $\mathrm{GeS}_{2}$ is that $\mathrm{S}$ in $\mathrm{Li}_{2} \mathrm{~S}$ is the fully ionic $\mathrm{S}=$ sulfide anion and the $\mathrm{S}$ in the $\mathrm{GeS}_{2}$ is the fully covalent $\mathrm{BS}, \equiv \mathrm{Ge}-\mathrm{S}-\mathrm{Ge} \equiv$, and hence the binding energy of the covalent BS is higher than that of the ionic sulfide. For the S2p spectra of sulfur species, there is a doublet consisting of $S 2 p_{3 / 2}$ and $S 2 p_{1 / 2}$ spin-orbit coupled electrons in the intensity ratio of $2: 1$. The $\mathrm{S} 2 \mathrm{p}$ core peaks of $\mathrm{Li}_{2} \mathrm{~S}$ show one doublet. This doublet arises from the $\mathrm{Li}_{2} \mathrm{~S}$ bonding and means that only the $\mathrm{Li}_{2} \mathrm{~S}$ bonding exists. This result agrees well with the literature data(Foix et al., 2001).

If $\mathrm{Li}_{2} \mathrm{~S}$ was significantly contaminated by oxygen, the deconvoluted $\mathrm{S} 2 \mathrm{p}$ spectra would be expected to show additional peaks related to sulfite $\mathrm{SO}_{3}{ }^{2-}(166 \mathrm{eV})$ and/or sulfate $\mathrm{SO}_{4}{ }^{2-}$ $(172 \mathrm{eV})$ contamination(Volynsky et al., 2001). Both the $\mathrm{Li}_{2} \mathrm{~S}$ and $\mathrm{GeS}_{2}$ materials do not show significant peaks at $166 \mathrm{eV}$ and $172 \mathrm{eV}$ and suggests that these materials are of high purity. The deconvoluted S2p core peaks of the $\mathrm{GeS}_{2}$ also show as expected only one doublet arising from the single bridging sulfur structure, $\equiv \mathrm{Ge}-\mathrm{S}-\mathrm{Ge} \equiv$.
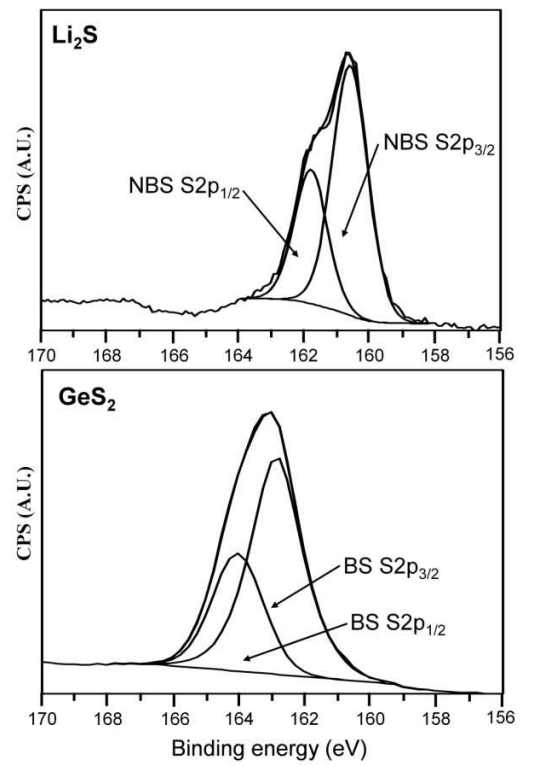

Fig. 12. Deconvoluted S2p core XPS spectra for $\mathrm{Li}_{2} \mathrm{~S}$ and $\mathrm{GeS}_{2}$ powder.

\subsubsection{Target material analysis}

After the target materials for RF sputtering were made using $\mathrm{nLi}_{2} \mathrm{~S}+\mathrm{GeS}_{2}, \mathrm{n}=1,2$ and 3 , their compositions were determined by XPS. The compositional data of the three target materials are shown in Table (4). The target materials show $\mathrm{C}$ and $\mathrm{O}$ contents and therefore the $\mathrm{Li}, \mathrm{Ge}$ and $\mathrm{S}$ contents are lower than the expected values. If $\mathrm{C}$ and $\mathrm{O}$ elements are ignored, the compositional data of $\mathrm{Li}, \mathrm{Ge}$ and $\mathrm{S}$ for all three target materials nearly match with the expected values. Although the XPS compositional data are different between the collected and expected data, the differences are within the confidence error limit, $\pm 3 \%$. Considering the $\pm 3 \%$ error of the XPS data, the small Li deficiency can be ignored. 
Ar etching treatments were not performed to remove surface $\mathrm{C}$ and $\mathrm{O}$ because the target materials were in the form of powders and Ar etching does not work well for powders that do not have large flat smooth surfaces. The deconvoluted S2p spectra of the three target materials are shown in Figure (13).

\begin{tabular}{ccccccc}
\hline At $\%$ & Li1s & Ge2p3 & S2p & C1s & O1s & Comments \\
\hline \multirow{2}{*}{ ii $_{2} \mathrm{GeS}_{3}$} & 26.1 & 16.4 & 41.3 & 10.3 & 5.9 & As-prepared \\
target & 30.4 & 19.1 & 48.1 & - & - & Ignoring C and O \\
& 33.3 & 16.7 & 50.0 & 0 & 0 & Expected values \\
\hline \multirow{2}{*}{ iiGeS$_{4}$} & 36.5 & 9.6 & 40.2 & 8.6 & 5.1 & As-prepared \\
Target & 42.3 & 11.1 & 46.6 & - & - & Ignoring C and O \\
& 44.4 & 11.2 & 44.4 & 0.0 & 0.0 & Expected values \\
\hline Li $_{6} \mathrm{GeS}_{5}$ & 40.4 & 8.0 & 37.2 & 6.5 & 7.9 & As-prepared \\
target & 47.2 & 9.3 & 43.5 & - & - & Ignoring C and O \\
& 50.0 & 8.3 & 41.7 & 0 & 0 & Expected values \\
\hline
\end{tabular}

Table 4. XPS compositional analysis of the $\mathrm{Li}_{2} \mathrm{GeS}_{3}, \mathrm{Li}_{4} \mathrm{GeS}_{4}$ and $\mathrm{Li}_{6} \mathrm{GeS}_{5}$ target materials.

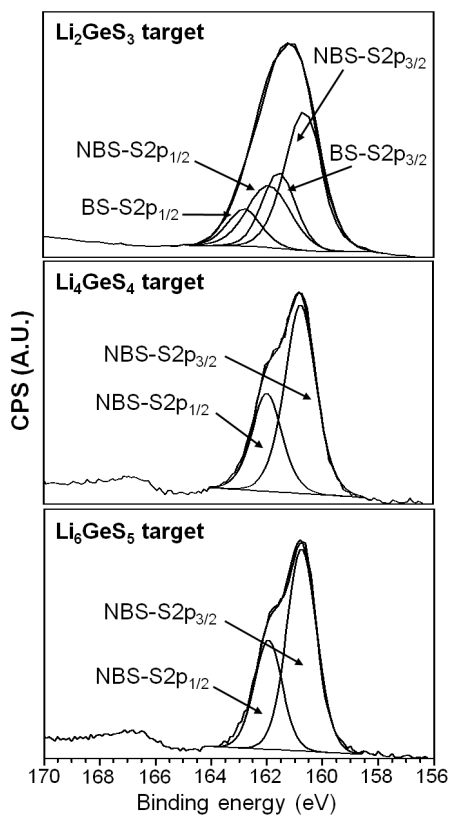

Fig. 13. Deconvoluted S2p core XPS spectra of the $\mathrm{Li}_{2} \mathrm{GeS}_{3}(\mathrm{a}), \mathrm{Li}_{4} \mathrm{GeS}_{4}(\mathrm{~b}), \mathrm{Li}_{6} \mathrm{GeS}_{5}$ (c) target materials.

From the spectra in Figure (13), the binding energies of the NBS, $\equiv \mathrm{Ge}-\mathrm{S}-\mathrm{Li}^{+}$and BS, $\equiv \mathrm{Ge}-\mathrm{S}-\mathrm{Ge} \equiv$ can be obtained. By comparing these XPS spectra to that of the standard materials, it can be determined that the sulfur spectra do not contain peaks related to sulfite 
$\mathrm{SO}_{3}{ }^{2-}$ or sulfate $\mathrm{SO}_{4}{ }^{2-}$ anions which would be shifted to significantly higher binding energies due to their $\mathrm{S}^{+4}$ and $\mathrm{S}^{+6}$ oxidation states, respectively. This suggests that although the target materials show some oxygen content as shown in Table (5), the contamination may only be on the surface. The low oxygen content is associated with the high purity of the starting materials as well as the fact that the target materials were made in a $\mathrm{N}_{2}$ filled high quality glovebox. As shown in Figure (13), while two doublets appear in the deconvoluted S2p core peaks of the $\mathrm{Li}_{2} \mathrm{GeS}_{3}$ target material indicating that there are two chemically distinct surface species, the $\mathrm{Li}_{4} \mathrm{GeS}_{4}$ and $\mathrm{Li}_{6} \mathrm{GeS}_{5}$ targets show only one doublet indicating a single chemical species for sulfur.

\begin{tabular}{ccc}
\hline Materials & $E_{\mathrm{b}} \mathrm{S}_{2} \mathrm{p}_{3 / 2-1 / 2}(\mathrm{eV})$ & Ratio \\
\hline $\mathrm{GeS}_{2}$ & $162.8-164.0$ & $100 \% \mathrm{BS}$ \\
$\mathrm{Li}_{2} \mathrm{GeS}_{3}$ target & $160.9-162.1$ & $65.9 \% \mathrm{NBS}$ \\
& $161.7-162.9$ & $34.1 \% \mathrm{BS}$ \\
$\mathrm{Li}_{4} \mathrm{GeS}_{4}$ target & $160.8-162.0$ & $100 \% \mathrm{NBS}$ \\
& & $0 \% \mathrm{BS}$ \\
$\mathrm{Li}_{6} \mathrm{GeS}_{5}$ target & $160.7-161.9$ & $100 \% \mathrm{NBS}$ \\
& & $0 \% \mathrm{BS}$ \\
$\mathrm{Li}_{2} \mathrm{~S}$ & $160.5-161.7$ & $100 \% \mathrm{NBS}$ \\
\hline
\end{tabular}

Table 5. The XPS binding energies and the ratio of NBS to BS for the starting and target materials.

The binding energies of sulfur in the target compositions and the NBS and BS ratios of the three target materials are shown in Table (5). In order to compare the chemical shifts, the binding energies of the $\mathrm{GeS}_{2}$ and $\mathrm{Li}_{2} \mathrm{~S}$ are also listed in Table (5).

While the binding energy of $\mathrm{S}$ in $\mathrm{GeS}_{2}$ shows the highest value due to its BS structure, the binding energy of $\mathrm{S}$ in $\mathrm{Li}_{2} \mathrm{~S}$ shows the lowest value. The binding energies of the target materials are similar to one another and, as expected, are between that of $\mathrm{GeS}_{2}$ and $\mathrm{Li}_{2} \mathrm{~S}$. In the $\mathrm{S}$ XPS spectrum of the $\mathrm{Li}_{2} \mathrm{GeS}_{3}$ target, the low energy doublet is assigned to the NBS and the other higher energy doublet is assigned to the BS. For the $\mathrm{Li}_{2} \mathrm{GeS}_{3}$ target material, the ratio of the NBS to BS is $65.3 \%$ to $34.7 \%$. The expected ratio of NBS to BS in the $\mathrm{Li}_{2} \mathrm{GeS}_{3}$ target composition agrees well with that calculated from the composition of $67 \%$ to $33 \%$.(Foix et al., 2002) Theoretically, the ratio of the NBS to BS in the $\mathrm{Li}_{4} \mathrm{GeS}_{4}$ target should be $100 \%$ and $0 \%$, respectively.

As shown in Table (5), the $\mathrm{Li}_{4} \mathrm{GeS}_{4}$ target material shows $100 \%$ NBS to $0 \%$ BS ratio. Additionally and as expected, the $\mathrm{Li}_{6} \mathrm{GeS}_{5}$ target material shows $100 \% \mathrm{NBS}$ and $0 \% \mathrm{BS}$. As described above, $\mathrm{Li}_{2} \mathrm{~S}$ consists of only the $\mathrm{S}=$ anion whereas $\mathrm{Li}_{4} \mathrm{GeS}_{4}$ consists of $100 \% \mathrm{NBS}$. From the composition, it is expected that the $\mathrm{Li}_{6} \mathrm{GeS}_{5}$ target should be composed of an equimolar mixture of $\mathrm{Li}_{2} \mathrm{~S}$ and $\mathrm{Li}_{4} \mathrm{GeS}_{4}$. However, the XPS spectra data shown in Table (5) shows that $\mathrm{Li}_{6} \mathrm{GeS}_{5}$ consists of only $100 \%$ NBS and $0 \%$ BS. Strictly speaking, $\mathrm{Li}_{6} \mathrm{GeS}_{5}$ should consist of $\mathrm{Li}_{4} \mathrm{GeS}_{4}$ which has $100 \% \mathrm{NBS}$ and $\mathrm{Li}_{2} \mathrm{~S}$ which has $100 \%$ ionic sulfur, $\mathrm{S}=$. While the binding energies of the $S=$ anion and the NBS are very close, the resolution of our XPS instrument appears to be insufficient to differentiate the chemical shift of $S=$ anion and the NBS unit, $\equiv$ Ge-S- $-\mathrm{Li}^{+}$. 


\subsubsection{Lithium thio-germanate thin-film analysis}

After sputtering thin-films on Ni-coated Si substrates in Ar atmospheres, they were characterized by XPS to determine their compositions and chemical shifts. It was found that a Ni protective layer on the Si was necessary to prevent reaction of the Si with the Li which produces highly Li deficient films. This is described below in the experimental section. The compositional data of all of the thin-films sputtered in Ar atmospheres using the three different conditions are shown in Table (6).

\begin{tabular}{ccccccc}
\hline At $\%$ & Li1s & Ge2p3 & S2p & C1s & O1s & Comments \\
\hline $\mathrm{Li}_{2} \mathrm{GeS}_{3}$ & 27.2 & 8.5 & 37.1 & 18.6 & 8.6 & As-prepared \\
thin-film & 32.6 & 15.9 & 47.8 & 0.0 & 3.7 & Etching for 1 min. \\
$\mathrm{n}=1$ & 31.7 & 16.1 & 48.1 & 0.0 & 4.1 & Etching for 5 min. \\
& 33.3 & 16.7 & 50.0 & 0.0 & 0.0 & Expected values \\
\hline $\mathrm{Li}_{4} \mathrm{GeS}_{4}$ & 31.0 & 5.5 & 32.1 & 18.3 & 13.1 & As-prepared \\
thin-film & 40.6 & 12.6 & 41.3 & 0.0 & 5.5 & Etching for $1 \mathrm{~min}$. \\
$\mathrm{n}=2$ & 41.9 & 12.9 & 40.5 & 0.0 & 4.7 & Etching for 5 min. \\
& 44.4 & 11.2 & 44.4 & 0.0 & 0.0 & Expected values \\
\hline $\mathrm{Li} 6 \mathrm{GeS}$ & 35.9 & 4.9 & 33.2 & 14.7 & 11.3 & As-prepared \\
thin-film & 43.7 & 8.9 & 41.8 & 0.0 & 5.6 & Etching for 1 min. \\
$\mathrm{n}=3$ & 44.6 & 11.1 & 41.2 & 0.0 & 3.1 & Etching for 5 min. \\
& 50.0 & 8.3 & 41.7 & 0.0 & 0.0 & Expected values \\
\hline
\end{tabular}

Table 6. XPS compositional analysis of the $\mathrm{Li}_{2} \mathrm{GeS}_{3}, \mathrm{Li}_{4} \mathrm{GeS}_{4}$ and $\mathrm{Li}_{6} \mathrm{GeS}_{5}$ thin-film grown on Ni-coated Si substrates in an Ar atmosphere.

For the as-prepared thin-films, the $\mathrm{C}$ and $\mathrm{O}$ contents are slightly higher than those of the targets and the $\mathrm{Li}, \mathrm{Ge}$ and $\mathrm{S}$ contents are slightly lower than their expected values. It is assumed that this arises due to the intrinsically higher chemical reactivity of the surface of thin-films compared to bulk materials. In order to obtain more accurate compositional data of the thin-films, Ar etching was performed on the thin-film surfaces for $1 \mathrm{~min}$. and $5 \mathrm{~min}$. at a rate of $\sim 1 \mathrm{~nm} / \mathrm{min}$. As shown in Table (6), after Ar etching for $1 \mathrm{~min}$. the $C$ content in the thin-films reduced to $0 \%$ and the $\mathrm{O}$ content decreased significantly. Although some $\mathrm{O}$ content still exists in the thin-films, the $\mathrm{Li}, \mathrm{Ge}$, and $\mathrm{S}$ contents in the thin-films are very close to their expected values. In order to examine deeper profiles of the thin-film, Ar etching for $5 \mathrm{~min}$. was performed at $\sim 1 \mathrm{~nm} / \mathrm{min}$. etching rate. After Ar etching for $5 \mathrm{~min}$. was performed, the compositional data are almost the same compared to the data obtained after Ar etching for 1 minute. This suggests that the thin-films show high uniformity and quality except for the top $1 \mathrm{~nm}$ of the surface. Previous literature reported(Yamashita, M., et al., 1996a) that thio-germanate thin-films produced from $\mathrm{Li}_{2} \mathrm{~S}+\mathrm{Ga}_{2} \mathrm{~S}_{3}+\mathrm{GeS}_{2}$ by sputtering showed severe Li deficiency. While these ternary thin-films showed as high as $\sim 30$ to $40 \% \mathrm{Li}$ deficiency compared to the $\mathrm{Li}$ in target composition, the thin-films produced in this study only show $\sim 3-5 \%$ Li deficiency. The compositions of the thin-films in this study are consistent with those of the target and it is therefore assumed that the sputtering conditions 
reported here are optimized and the thin-film compositions are reliable. In order to determine the fractions of NBS and BS in the thin-films, the deconvoluted S2p core peaks for the $\mathrm{Li}_{2} \mathrm{GeS}_{3}, \mathrm{Li}_{4} \mathrm{GeS}_{4}$, and $\mathrm{Li}_{6} \mathrm{GeS}_{5}$ as-prepared thin-films (without Ar etching treatment) are shown in Figure (14).

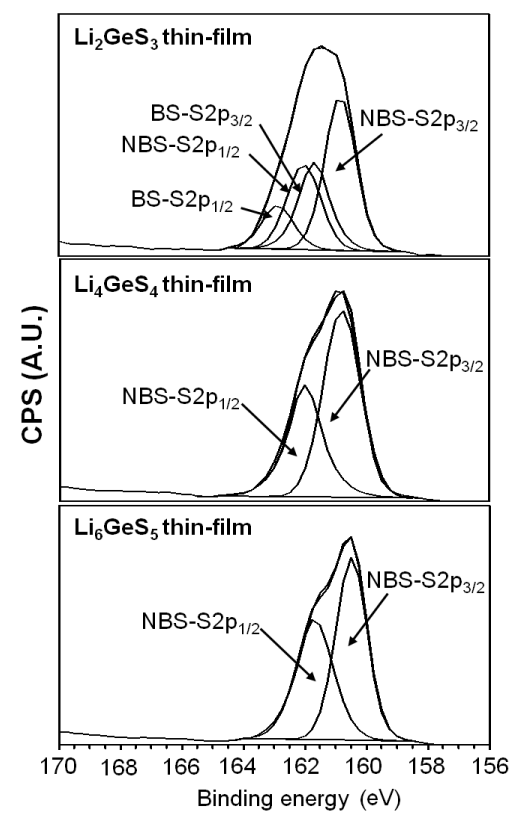

Fig. 14. Deconvoluted S2p core peaks for the $\mathrm{Li}_{2} \mathrm{GeS}_{3}, \mathrm{Li}_{4} \mathrm{GeS}_{4}$, and $\mathrm{Li}_{6} \mathrm{GeS}_{5}$ thin-films grown in Ar atmospheres.

While the XPS spectra of the $\mathrm{Li}, \mathrm{Ge}$, and $\mathrm{S}$ species are unchanged in binding energy with and without Ar etching, Ar etching could reform the chemistry of the Ar sputtered surface. For this reason, it is believed that a better representation of the bonding chemistries, the chemical speciation, of these thin-films are therefore found in the as-prepared surfaces of the thin-films. For example, Foix et al. reported the fractions of NBS and BS in lithium thio-germanate and thio-arsenate bulk glasses and to do so they broke the glasses in the glove box and they characterized the newly exposed broken surface of the glasses without Ar etching(Foix et al., 2001; Volynsky et al., 2001).

In addition, Atashbar et al. reported the XPS deconvoluted data of $\mathrm{TiO}_{2}$ thin-films without Ar etching(Atashbar et al., 1998). These approaches suggest that although accurate compositional data could be obtained from the Ar etched surface, the data could also be to use the XPS deconvoluted structural analysis is also obtained from the as-prepared surface without Ar etching. The fractions of the NBS and BS in the thin-films were calculated from Figure (14) and are shown in Table (7). In Figure (14) as described above, the $\mathrm{Li}_{2} \mathrm{GeS}_{3}$ thin-film shows two doublets. The doublet on the low energy side (lower binding energy) is attributed to the NBS and the other doublet on the high energy side (higher binding energy) is associated to BS. The ratios of the NBS and BS in the $\mathrm{Li}_{2} \mathrm{GeS}_{3}$ thin-film are $64.4 \% \mathrm{NBS}$ and 
$35.6 \%$ BS, respectively. Although the ratios are not exactly the same as the expected values, $67 \%$ NBS and $33 \%$ BS, the differences between those of the $\mathrm{Li}_{2} \mathrm{GeS}_{3}$ thin-film and expected values are within the error range of $\pm 3 \%$.

In addition, the ratios of the NBS and BS in the $\mathrm{Li}_{2} \mathrm{GeS}_{3}$ target and thin-film are very close. This suggests that the target compositions and thin-film compositions are quite consistent. While the deconvoluted $\mathrm{S} 2 \mathrm{p}$ core spectra of the $\mathrm{Li}_{2} \mathrm{GeS}_{3}$ thin-film show two doublets, the deconvoluted $\mathrm{S} 2 \mathrm{p}$ core spectra of the $\mathrm{Li}_{4} \mathrm{GeS}_{4}$ and $\mathrm{Li}_{6} \mathrm{GeS}_{5}$ thin-films show only one doublet. As described above, the $\mathrm{Li}_{4} \mathrm{GeS}_{4}$ and $\mathrm{Li}_{6} \mathrm{GeS}_{5}$ targets also show only one doublet from the NBS. In agreement with these $\mathrm{Li}_{4} \mathrm{GeS}_{4}$ and $\mathrm{Li}_{6} \mathrm{GeS}_{5}$ targets, the two thin-films show only one doublet arising from only NBS structures.

Recently, a few XPS studies of Ge-S thin-films have been reported in the literature but the analyzes were very brief.(Gonbeau et al., 2005; Mitkova et al., 2004) However, in this study, the compositions and chemical shifts of the Li-Ge-S thin-films have been thoroughly investigated(Gonbeau et al., 2005; Mitkova et al., 2004). As shown in Figure (14), the spectrum for $\mathrm{GeS}_{2}$ shows a higher binding energy than those of $\mathrm{Li}_{2} \mathrm{~S}$ and the thinfilms because the $\mathrm{GeS}_{2}$ is assigned to the $\mathrm{BS}$ as described above. As the $\mathrm{Li}_{2} \mathrm{~S}$ content increases, the binding energy of the thin-films shifts to lower values than that of $\mathrm{GeS}_{2}$. While the binding energies of the thin-films are similar to one another, with the $S$ peak for $\mathrm{Li}_{2} \mathrm{GeS}_{3}$ being broader than that for $\mathrm{Li}_{4} \mathrm{GeS}_{4}$ and $\mathrm{Li}_{6} \mathrm{GeS}_{5}$ due to the presence of both BS and NBS, the binding energies of the thin-films slightly shifted to lower values. As expected, the binding energy of the $\mathrm{Li}_{2} \mathrm{~S}$ shows the lowest binding energy of the materials studied here.

\begin{tabular}{cccc}
\hline Thin-films & $E_{\mathrm{b}} \mathrm{S}_{2} \mathrm{p}_{3 / 2-1 / 2}(\mathrm{eV})$ & NBS : BS & Expected values \\
\hline $\mathrm{Li}_{2} \mathrm{GeS}_{3}$ & $160.9-162.1$ & $65.4 \% \mathrm{NBS}$ & $66.7 \% \mathrm{NBS}$ \\
as-prepared & $161.5-162.7$ & $34.6 \% \mathrm{BS}$ & $33.3 \% \mathrm{BS}$ \\
\hline $\mathrm{Li}_{4} \mathrm{GeS}_{4}$ & $160.8-162.0$ & $100 \% \mathrm{NBS}$ & $100 \% \mathrm{NBS}$ \\
as-prepared & & $0 \% \mathrm{BS}$ & $0 \% \mathrm{BS}$ \\
\hline $\mathrm{Li}_{6} \mathrm{GeS}_{5}$ & $160.7-161.9$ & $100 \% \mathrm{NBS}$ & $100 \% \mathrm{NBS}$ \\
as-prepared & & $0 \% \mathrm{BS}$ & $0 \% \mathrm{BS}$ \\
\hline
\end{tabular}

Table 7. The XPS binding energies $\left(E_{b}\right)$ and fractions of NBS to BS of the $\mathrm{Li}_{2} \mathrm{GeS}_{3}, \mathrm{Li}_{4} \mathrm{GeS}_{4}$ and $\mathrm{Li}_{6} \mathrm{GeS}_{5}$ thin-films.

\section{Conclusion}

For the first time, lithium thio-germanate thin-film electrolytes for the solid-state lithium-ion batteries grown by RF sputtering were characterized thoroughly by XRD, FE-SEM, Raman, IR, impedance spectroscopy, and XPS. From the XRD pattern, the $\mathrm{Li}_{2} \mathrm{GeS}_{3}(\mathrm{n}=1)$ target was amorphous and the $\mathrm{Li}_{4} \mathrm{GeS}_{4}(\mathrm{n}=2)$ and $\mathrm{Li}_{6} \mathrm{GeS}_{5}(\mathrm{n}=3)$ targets were crystalline as expected from compositions. The $\mathrm{Li}_{6} \mathrm{GeS}_{5}$ target appears to be consistent with an equi-molar mixture of $\mathrm{Li}_{2} \mathrm{~S}$ and $\mathrm{Li}_{4} \mathrm{GeS}_{4}$. FE-SEM of the thin films deposited on Ni-coated Si substrates shows a mirror-like surface without cracks or pits. The Raman spectra of all of the thin-films do not show sharp peaks, rather they show much broader peaks compared to those of crystalline targets $\left(\mathrm{Li}_{4} \mathrm{GeS}_{4}\right.$ and $\left.\mathrm{Li}_{6} \mathrm{GeS}_{5}\right)$ and are consistent with the thin-films being amorphous. This 
shows that RF sputtering can be used to extend the formation range of amorphous materials from $\sim 50$ to $\sim 75$ mole $\% \mathrm{Li}_{2} \mathrm{~S}$.

The Raman and IR spectra also showed the structural and compositional consistency between targets and the thin-films and that the $\mathrm{Li}_{2} \mathrm{~S}$ content of thin-films increased as expected with $\mathrm{Li}_{2} \mathrm{~S}$ addition in the targets. These results suggest that the thin-films did not show significant Li deficiency as seen in previous reports after sputtering.

The ionic conductivities of the thin-films at $25{ }^{\circ} \mathrm{C}$ obtained are the highest reported for $\mathrm{Li}^{+}$ion in a glassy materials and are at least two orders of magnitude higher than those of commercial LiPON thin-film electrolytes. The thin-films materials are stable over wide temperature ranges, so that it can be said that the lithium-ion batteries based on these sulfides materials are very stable over wide temperature ranges and are very promising to apply to commercial products. The purpose of the XPS work was to provide information on the compositional data and the structures of lithium thio-germanate thin-films by means of XPS studies. High purity starting materials were used and targets were produced under well-calibrated and optimized conditions.

For the first time, highly reproducible compositions and chemical shifts of the starting materials, targets, and thin-films of $\mathrm{nLi}_{2} \mathrm{~S}+\mathrm{GeS}_{2}$ materials were determined by XPS. Although the as-prepared thin-films contained $\mathrm{C}$ and $\mathrm{O}$ on the surface, the thin-films showed that the $\mathrm{C}$ was completely removed and $\mathrm{O}$ content decreased significantly after Ar etching for $1 \mathrm{~min}$. This suggests that the thin-films were contaminated by $C$ only at the top $1 \mathrm{~nm}$ of the surface and the thin-films contained low oxygen contents in the interior of the film. After Ar etching, the compositions of the thin-films were very close to those expected. Therefore, the thin-films produced by sputtering are very close to their corresponding target materials. Thio-germanate thin-film materials have not been as widely studied as their oxide materials because of the difficulties in preparation. However, in this study, the lithium thiogermanate thin-films were successfully prepared and the compositional data and the chemical shifts were carefully characterized by XPS.

By successfully making thin-films of high quality and high conductivity, they can be applied as thin-film electrolytes for solid-state thin-film batteries. Further extensive effort for solid-state full battery fabrication, however, is needed before this thin-film electrolyte is put to practical use.

\section{Acknowledgement}

This research was supported by NSF under grant number DMR-0312081 and this research support is gratefully acknowledged. The authors thank Mr. James Anderegg who helped collect all of the XPS spectra and assisted with the experimental details to load and examine the samples without contamination.

\section{References}

Abe, T., et al., (2005), Lithium-Ion Transfer at the Interface Between Lithium-Ion Conductive Ceramic Electrolyte and Liquid Electrolyte-A Key to Enhancing the Rate Capability of Lithium-Ion Batteries: Journal of the Electrochemical Society, Vol. 152, No. 11, pp. A2151-A2154, 00134651. 
Akridge, J. R., and H. Vourlis, (1986), Solid-State Batteries Using Vitreous Solid Electrolytes: Solid State Ionics, Vol. 18-9, pp. 1082-1087, 0167-2738.

Akridge, J. R., and H. Vourlis, (1988), Performance of Li/TiS2 solid state batteries using phosphorous chalcogenide network former glasses as solid electrolyte: Solid State Ionics, Vol. 28-30, No. Part 1, pp. 841-846, 0167-2738.

Albano, F., et al., (2008), A fully integrated microbattery for an implantable microelectromechanical system: Journal of Power Sources, Vol. 185, No. 2, pp. 1524-1532, 0378-7753.

Amatucci, G. G., et al., (1996), $\mathrm{CoO}_{2}$, the end member of the $\mathrm{Li}_{\mathrm{x}} \mathrm{CoO}_{2}$ solid solution: Journal of the Electrochemical Society, Vol. 143, No. 3, pp. 1114-1123, 0013-4651.

Andersson, A. S., et al., (2000), Lithium extraction/insertion in $\mathrm{LiFePO}_{4}$ : an X-ray diffraction and Mossbauer spectroscopy study: Solid State Ionics, Vol. 130, No. 1-2, pp. 41-52, 0167-2738.

Angell, C. A., (1983), Fast ion motion in glassy and amorphous materials: Solid State Ionics, Vol. 9-10, No. DEC, pp. 3-16, 0167-2738.

Aotani, N., et al., (1994), Synthesis and electrochemical properties of lithium ion conductive glass, $\mathrm{Li}_{3} \mathrm{PO}_{4} \mathrm{Li}_{2} \mathrm{SSiS}_{2}$ : Solid State Ionics, Vol. 68, No. 1-2, pp. 35-39, 0167-2738.

Appetecchi, G. B., et al., (2003), Investigation of swelling phenomena in poly(ethylene oxide)-based polymer electrolytes-III. Preliminary battery tests: Journal of the Electrochemical Society, Vol. 150, No. 3, pp. A301-A305, 0013-4651.

Armand, M., and J. M. Tarascon, (2008), Building better batteries: Nature, Vol. 451, No. 7179, pp. 652-657, 0028-0836.

Atashbar, M. Z., et al., (1998), XPS study of Nb-doped oxygen sensing $\mathrm{TiO}_{2}$ thin films prepared by sol-gel method: Thin Solid Films, Vol. 326, No. 1-2, pp. 238-244, 00406090.

Baba, M., et al., (2001), Fabrication and clcctrochemical characteristics of all-solid-state lithium-ion rechargeable batteries composed of $\mathrm{LiMn}_{2} \mathrm{O}_{4}$ positive and $\mathrm{V}_{2} \mathrm{O}_{5}$ negative electrodes: Journal of Power Sources, Vol. 97-8, pp. 798-800, 0378-7753.

Baba, M., et al., (1999), Fabrication and electrochemical characteristics of all- solid-state lithium-ion batteries using $\mathrm{V}_{2} \mathrm{O}_{5}$ thin films for both electrodes: Electrochemical and Solid State Letters, Vol. 2, No. 7, pp. 320-322, 1099-0062.

Bao, Q., et al., (2005), Pulsed laser deposition and its current research status in preparing hydroxyapatite thin films: Applied Surface Science, Vol. 252, No. 5, pp. 1538-1544, 0169-4332.

Barker, J., et al., (2003), Lithium iron(II) phospho-olivines prepared by a novel carbothermal reduction method: Electrochemical and Solid State Letters, Vol. 6, No. 3, pp. A53-A55, 1099-0062.

Barrau, B., et al., (1980), Glass formation, structure and ionic conduction in the $\mathrm{Na}_{2} \mathrm{~S}-\mathrm{GeS}_{2}$ system: Journal of Non-Crystalline Solids, Vol. 37, No. 1, pp. 1-14, 0022-3093.

Bates, J. B., et al., (1993), Fabrication and characterization of amorphous lithium electrolyte thin films and rechargeable thin-film batteries: Journal of Power Sources, Vol. 43, No. 1-3, pp. 103-110, 0378-7753.

Bates, J. B., et al., (2000a), Thin-film lithium and lithium-ion batteries: Solid State Ionics, Vol. 135, No. 1-4, pp. 33-45, 0167-2738.

Bates, J. B., et al., (2000b), Preferred Orientation of Polycrystalline $\mathrm{LiCoO}_{2}$ Films: Journal of The Electrochemical Society, Vol. 147, No. 1, pp. 59-70, 
Birke, P., et al., (1999), A first approach to a monolithic all solid state inorganic lithium battery: Solid State Ionics, Vol. 118, No. 1-2, pp. 149-157, 0167-2738.

Bobeico, E., et al., (2003), P-type strontium-copper mixed oxide deposited by e-beam evaporation: Thin Solid Films, Vol. 444, No. 1-2, pp. 70-74, 0040-6090.

Boukamp, B. A., and R. A. Huggins, (1978), Fast ionic conductivity in lithium nitride: Materials Research Bulletin, Vol. 13, No. 1, pp. 23-32, 0025-5408.

Bourderau, S., et al., (1999), Amorphous silicon as a possible anode material for Li-ion batteries: Journal of Power Sources, Vol. 81, pp. 233-236, 0378-7753.

Bronger, W., et al., (1964), Zur Kenntnis Der Niccolate Der Alkalimetalle: Zeitschrift Fur Anorganische Und Allgemeine Chemie, Vol. 333, No. 4-6, pp. 188-200, 0044-2313.

Buiel, E., and J. R. Dahn, (1999), Li-insertion in hard carbon anode materials for Li-ion batteries: Electrochimica Acta, Vol. 45, No. 1-2, pp. 121-130, 0013-4686.

Campbell, S. A., et al., (1990), The Electrochemical-Behavior of Tetrahydrofuran and Propylene Carbonate without Added Electrolyte: Journal of Electroanalytical Chemistry, Vol. 284, No. 1, pp. 195-204, 0022-0728.

Cernosek, Z., et al., (1997), Raman scattering in $\mathrm{GeS}_{2}$ glass and its crystalline polymorphs compared: Journal of Molecular Structure, Vol. 435, No. 2, pp. 193-198, 0022-2860.

Chang, C. C., et al., (2000), Synthesis and electrochemical characterization of divalent cationincorporated lithium nickel oxide: Journal of the Electrochemical Society, Vol. 147, No. 5, pp. 1722-1729, 0013-4651.

Chhowalla, M., et al., (2001), Growth process conditions of vertically aligned carbon nanotubes using plasma enhanced chemical vapor deposition: Journal of Applied Physics, Vol. 90, No. 10, pp. 5308-5317, 0021-8979.

Chiang, Y. M., et al., (1998), Synthesis of $\mathrm{LiCoO}_{2}$ by decomposition and intercalation of hydroxides: Journal of the Electrochemical Society, Vol. 145, No. 3, pp. 887-891, 00134651.

Cho, K., et al., (2007), Fabrication of $\mathrm{Li}_{2} \mathrm{O}-\mathrm{B}_{2} \mathrm{O}_{3}-\mathrm{P}_{2} \mathrm{O}_{5}$ solid electrolyte by aerosol flame deposition for thin film batteries: Solid State Ionics, Vol. 178, No. 1-2, pp. 119-123, 0167-2738.

Chowdari, B. V. R., et al., (2001), Cathodic behavior of (Co, Ti, Mg)-doped $\mathrm{LiNiO}_{2}$ : Solid State Ionics, Vol. 140, No. 1-2, pp. 55-62, 0167-2738.

Chrisey, D. B., and G. K. Hubler, (1994), Pulsed laser deposition of thin films: New York, J. Wiley, 613 p., 0471592188.

Croce, F., et al., (2001), A High-Rate, Long-Life, Lithium Nanocomposite Polymer Electrolyte Battery: Electrochemical and Solid-State Letters, Vol. 4, No. 8, pp. A121-A123,

Crowther, O., and A. C. West, (2008), Effect of electrolyte composition on lithium dendrite growth: Journal of the Electrochemical Society, Vol. 155, No. 11, pp. A806-A811, 00134651.

Cui, P., et al., (2011), Preparation and characteristics of Sb-doped $\mathrm{LiNiO}_{2}$ cathode materials for Li-ion batteries: Journal of Physics and Chemistry of Solids, Vol. 72, No. 7, pp. 899903, 0022-3697.

Cunningham, P. T., et al., (1972), Phase Equilibria in Lithium-Chalcogen Systems: Journal of The Electrochemical Society, Vol. 119, No. 11, pp. 1448-1450,

Dahn, J. R., et al., (1991), Rechargeable $\mathrm{LiNiO}_{2}$ Carbon Cells: Journal of the Electrochemical Society, Vol. 138, No. 8, pp. 2207-2211, 0013-4651. 
David, W. I. F., et al., (1987), Structure Refinement of the Spinel-Related Phases $\mathrm{Li}_{2} \mathrm{Mn}_{2} \mathrm{O}_{4}$ and $\mathrm{Li}_{0.2} \mathrm{Mn}_{2} \mathrm{O}_{4}$ : Journal of Solid State Chemistry, Vol. 67, No. 2, pp. 316-323, 00224596.

Davidse, P. D., (1967), Theory and practice of RF sputtering: Vacuum, Vol. 17, No. 3, pp. 139145, 0042-207X.

Dickens, P. G., et al., (1979), Phase-Relationships in the Ambient-Temperature $\mathrm{Li}_{\mathrm{x}} \mathrm{V}_{2} \mathrm{O}_{5}$ System (0.1-Less-Than-X-Less-Than-1.0): Materials Research Bulletin, Vol. 14, No. 10, pp. 1295-1299, 0025-5408.

Dudney, N. J., (2000), Addition of a thin-film inorganic solid electrolyte (LiPON) as a protective film in lithium batteries with a liquid electrolyte: Journal of Power Sources, Vol. 89, No. 2, pp. 176-179, 0378-7753.

Dudney, N. J., (2005), Solid-state thin-film rechargeable batteries: Materials Science and Engineering B-Solid State Materials for Advanced Technology, Vol. 116, No. 3, pp. 245249, 0921-5107.

Dudney, N. J., et al., (1999), Nanocrystalline $\mathrm{Li}_{x} \mathrm{Mn}_{2-\mathrm{y}} \mathrm{O}_{4}$ cathodes for solid-state thin-film rechargeable lithium batteries: Journal of the Electrochemical Society, Vol. 146, No. 7, pp. 2455-2464, 0013-4651.

Elmoudane, M., et al., (2000), Glass-forming region in the system $\mathrm{Li}_{3} \mathrm{PO}_{4}-\mathrm{Pb}_{3}\left(\mathrm{PO}_{4}\right)_{2}-\mathrm{BiPO}_{4}$ $\left(\mathrm{Li}_{2} \mathrm{O}-\mathrm{PbO}-\mathrm{Bi}_{2} \mathrm{O}_{3}-\mathrm{P}_{2} \mathrm{O}_{5}\right)$ and its ionic conductivity: Materials Research Bulletin, Vol. 35, No. 2, pp. 279-287, 0025-5408.

Fauteux, D., et al., (1995), Lithium polymer electrolyte rechargeable battery: Electrochimica Acta, Vol. 40, No. 13-14, pp. 2185-2190, 0013-4686.

Fenton, D. E., et al., (1973), Complexes of Alkali-Metal Ions with Poly(Ethylene Oxide): Polymer, Vol. 14, No. 11, pp. 589-589, 0032-3861.

Foix, D., et al., (2002), Electronic structure of thiogermanate and thioarseniate glasses: experimental (XPS) and theoretical (ab initio) characterizations: Solid State Ionics, Vol. 154, pp. 161-173, 0167-2738.

Foix, D., et al., (2001), The structure of ionically conductive chalcogenide glasses: a combined NMR, XPS and ab initio calculation study: Solid State Sciences, Vol. 3, No. 1-2, pp. 235-243, 1293-2558.

Frumarova, B., et al., (1996), Synthesis and physical properties of the system $\left(\mathrm{GeS}_{2}\right)(80-\mathrm{x})$ $\left(\mathrm{Ga}_{2} \mathrm{~S}_{3}\right)(20): x$ Pr glasses: Optical Materials, Vol. 6, No. 3, pp. 217-223, 0925-3467.

Gao, Y. A., et al., (1998), Novel $\mathrm{LiNi}_{1-\mathrm{x}} \mathrm{Ti}_{\mathrm{x} / 2} \mathrm{Mg}_{\mathrm{x} / 2} \mathrm{O}_{2}$ compounds as cathode materials for safer lithium-ion batteries: Electrochemical and Solid State Letters, Vol. 1, No. 3, pp. 117-119, 1099-0062.

Gonbeau, D., et al., (2005), Photoinduced changes in the valence band states of $\mathrm{Ge}_{x} \mathrm{As}_{40-\mathrm{x}} \mathrm{S}_{60}$ thin films: Journal of Optoelectronics and Advanced Materials, Vol. 7, No. 1, pp. 341$344,1454-4164$.

Gummow, R. J., et al., (1994), Improved Capacity Retention in Rechargeable 4V Lithium Lithium Manganese Oxide (Spinel) Cells: Solid State Ionics, Vol. 69, No. 1, pp. 59-67, 0167-2738.

Gummow, R. J., et al., (1993), Lithium Extraction from Orthorhombic Lithium Manganese Oxide and the Phase-Transformation to Spinel: Materials Research Bulletin, Vol. 28, No. 12, pp. 1249-1256, 0025-5408.

Gummow, R. J., and M. M. Thackeray, (1994), An Investigation of Spinel-Related and Orthorhombic Limno2 Cathodes for Rechargeable Lithium Batteries: Journal of the Electrochemical Society, Vol. 141, No. 5, pp. 1178-1182, 0013-4651. 
Guyomard, D., and J. M. Tarascon, (1995), High-voltage stable liquid electrolytes for $\mathrm{Li}_{1+\times} \mathrm{Mn}_{2} \mathrm{O}_{4}$ carbon rocking-chair lithium batteries: Journal of Power Sources, Vol. 54, No. 1, pp. 92-98, 0378-7753.

Haizheng, T., et al., (2004), Raman spectroscopic study on the microstructure of $\mathrm{GeS}_{2}-\mathrm{Ga}_{2} \mathrm{~S}_{3}-$ KCl glasses: Journal of Molecular Structure, Vol. 697, No. 1-3, pp. 23-27, 0022-2860.

Hayashi, A., et al., (1996), Preparation of $\mathrm{Li}_{6} \mathrm{Si}_{2} \mathrm{~S}_{7}-\mathrm{Li}_{6} \mathrm{~B}_{4} \mathrm{X}_{9}(\mathrm{X}=\mathrm{S}, \mathrm{O})$ glasses by rapid quenching and their lithium ion conductivities: Solid State Ionics, Vol. 86-8, pp. 539$542,0167-2738$.

Hayashi, A., et al., (2005), All-solid-state lithium secondary batteries with $\mathrm{SnS}-\mathrm{P}_{2} \mathrm{~S}_{5}$ negative electrodes and $\mathrm{Li}_{2} \mathrm{~S}_{-} \mathrm{P}_{2} \mathrm{~S}_{5}$ solid electrolytes: Journal of Power Sources, Vol. 146, No. 1-2, pp. 496-500, 0378-7753.

Hayashi, A., et al., (2010), Development of sulfide glass-ceramic electrolytes for all-solidstate lithium rechargeable batteries: Journal of Solid State Electrochemistry, Vol. 14, No. 10, pp. 1761-1767, 1432-8488.

Hayashi, A., et al., (2009), All-solid-state lithium secondary batteries using nanocomposites of $\mathrm{NiS}$ electrode/ $\mathrm{Li}_{2} \mathrm{~S}-\mathrm{P}_{2} \mathrm{~S}_{5}$ electrolyte prepared via mechanochemical reaction: Journal of Power Sources, Vol. 189, No. 1, pp. 629-632, 0378-7753.

Hayashi, A., et al., (2003), All-solid-state Li/S batteries with highly conductive glass-ceramic electrolytes: Electrochemistry Communications, Vol. 5, No. 8, pp. 701-705, 1388-2481.

Hayashi, A., et al., (2002), Characterization of $\mathrm{Li}_{2} \mathrm{~S}-\mathrm{SiS}_{2}-\mathrm{Li}_{x} \mathrm{MO}_{\mathrm{y}}(\mathrm{M}=\mathrm{Si}, \mathrm{P}, \mathrm{Ge})$ amorphous solid electrolytes prepared by melt-quenching and mechanical milling: Solid State Ionics, Vol. 148, No. 3-4, pp. 381-389, 0167-2738.

Hintenlang, D. E., and P. J. Bray, (1985), NMR studies of $\mathrm{B}_{2} \mathrm{~S}_{3}$-based glasses: Journal of NonCrystalline Solids, Vol. 69, No. 2-3, pp. 243-248, 0022-3093.

Hirai, K., et al., (1995), Thermal and electrical properties of rapidly quenched glasses in the systems $\mathrm{Li}_{2} \mathrm{~S}_{-} \mathrm{SiS}_{2}-\mathrm{Li}_{\mathrm{x}} \mathrm{MO}_{\mathrm{y}}\left(\mathrm{Li}_{\mathrm{x}} \mathrm{MO}_{\mathrm{y}}=\mathrm{Li}_{4} \mathrm{SiO}_{4}, \mathrm{Li}_{2} \mathrm{SO}_{4}\right)$ : Solid State Ionics, Vol. 78, No. 3-4, pp. 269-273, 0167-2738.

Hirano, A., et al., (1995), Relationship between Nonstoichiometry and Physical-Properties in $\mathrm{LiNiO}_{2}$ : Solid State Ionics, Vol. 78, No. 1-2, pp. 123-131, 0167-2738.

Huang, H., et al., (2001), Approaching theoretical capacity of $\mathrm{LiFePO}_{4}$ at room temperature at high rates: Electrochemical and Solid State Letters, Vol. 4, No. 10, pp. A170-A172, 1099-0062.

Huang, H. T., et al., (1999), $\mathrm{LiAl}_{x} \mathrm{Co}_{1-\mathrm{x}} \mathrm{O}_{2}$ as $4 \mathrm{~V}$ cathodes for lithium ion batteries: Journal of Power Sources, Vol. 82, pp. 690-695, 0378-7753.

Iio, K., et al., (2002), Mechanochemical synthesis of high lithium ion conducting materials in the system $\mathrm{Li}_{3} \mathrm{~N}-\mathrm{SiS}_{2}$ : Chemistry of Materials, Vol. 14, No. 6, pp. 2444-2449, 0897-4756.

Iriyama, Y., et al., (2005), Charge transfer reaction at the lithium phosphorus oxynitride glass electrolyte/lithium cobalt oxide thin film interface: Solid State Ionics, Vol. 176, No. 31-34, pp. 2371-2376, 0167-2738.

Ito, $\mathrm{Y}$. , et al., (1983), Ionic conductivity of $\mathrm{Li}_{2} \mathrm{O}-\mathrm{B}_{2} \mathrm{O}_{3}$ thin films: Journal of Non-Crystalline Solids, Vol. 57, No. 3, pp. 389-400, 0022-3093.

Itoh, K., et al., (2006), Structural observation of $\mathrm{Li}_{2} \mathrm{~S}-\mathrm{GeS}_{2}$ superionic glasses: Physica B: Condensed Matter, Vol. 385-386, No. Part 1, pp. 520-522, 0921-4526.

Jak, M. J. G., et al., (1999a), Defect Structure of Li-Doped $\mathrm{BPO}_{4}$ : A Nanostructured Ceramic Electrolyte for Li-Ion Batteries: Journal of Solid State Chemistry, Vol. 142, No. 1, pp. 74-79, 0022-4596. 
Jak, M. J. G., et al., (1999b), Dynamically compacted all-ceramic lithium-ion batteries: Journal of Power Sources, Vol. 80, No. 1-2, pp. 83-89, 0378-7753.

Jamal, M., et al., (1999), Sodium ion conducting glasses with mixed glass formers $\mathrm{NaI}-\mathrm{Na}_{2} \mathrm{O}-$ $\mathrm{V}_{2} \mathrm{O}_{5}-\mathrm{B}_{2} \mathrm{O}_{3}$ : application to solid state battery: Materials Letters, Vol. 39, No. 1, pp. 28-32, 0167-577X.

Jeon, E. J., et al., (2001), Characterization of all-solid-state thin-film batteries with $\mathrm{V}_{2} \mathrm{O}_{5}$ thinfilm cathodes using ex situ and in situ processes: Journal of the Electrochemical Society, Vol. 148, No. 4, pp. A318-A322, 0013-4651.

Jin, B. J., et al., (2000), Violet and UV luminescence emitted from $\mathrm{ZnO}$ thin films grown on sapphire by pulsed laser deposition: Thin Solid Films, Vol. 366, No. 1-2, pp. 107-110, 0040-6090.

Jones, S. D., and J. R. Akridge, (1992), A thin film solid state microbattery: Solid State Ionics, Vol. 53-56, No. Part 1, pp. 628-634, 0167-2738.

Jones, S. D., and J. R. Akridge, (1996), A microfabricated solid-state secondary Li battery: Solid State Ionics, Vol. 86-8, pp. 1291-1294, 0167-2738.

Jourdaine, L., et al., (1988), Lithium solid state glass-based microgenerators: Solid State Ionics, Vol. 28-30, No. Part 2, pp. 1490-1494, 0167-2738.

Kaczmarek, S., (1996), Pulsed laser deposition - Today and tomorrow: Laser Technology V: Applications in Materials Sciences and Engineering, Vol. 3187, pp. 129-134

Kanehori, K., et al., (1986), Titanium Disulfide Films Fabricated by Plasma Cvd: Solid State Ionics, Vol. 18-9, pp. 818-822, 0167-2738.

Kanert, O., et al., (1994), Significant differences between nuclear-spin relaxation and conductivity relaxation in low-conductivity glasses: Physical Review B, Vol. 49, No. 1, pp. 76,

Kang, S. H., and J. B. Goodenough, (2000), $\mathrm{Li}\left[\mathrm{Li}_{\mathrm{y}} \mathrm{Mn}_{2-\mathrm{y}}\right] \mathrm{O}_{4}$ spinel cathode material prepared by a solution method: Electrochemical and Solid State Letters, Vol. 3, No. 12, pp. 536539, 1099-0062.

Kawamoto, Y., and M. Nishida, (1976), Ionic conduction in $\mathrm{As}_{2} \mathrm{~S}_{3}-\mathrm{Ag}_{2} \mathrm{~S}, \mathrm{GeS}_{2}-\mathrm{GeS}-\mathrm{Ag}_{2} \mathrm{~S}$ and $\mathrm{P}_{2} \mathrm{~S}_{5}-\mathrm{Ag}_{2} \mathrm{~S}$ glasses: Journal of Non-Crystalline Solids, Vol. 20, No. 3, pp. 393-404, 00223093.

Kenji, F., et al., Foliated natural graphite as the anode material for rechargeable lithium-ion cells: Journal of Power Sources, Vol. 69, No. 1-2, pp. 165-168, 0378-7753.

Kennedy, J. H., (1989), Ionically conductive glasses based on $\mathrm{SiS}_{2}$ : Materials Chemistry and Physics, Vol. 23, No. 1-2, pp. 29-50, 0254-0584.

Kim, C., et al., (2000), Microstructure and electrochemical properties of boron-doped mesocarbon microbeads: Journal of the Electrochemical Society, Vol. 147, No. 4, pp. 1257-1264, 0013-4651.

Kim, Y., et al., (2005), Glass formation in and structural investigation of $\mathrm{Li}_{2} \mathrm{~S}+\mathrm{GeS}_{2}+\mathrm{GeO}_{2}$ composition using Raman and IR spectroscopy: Journal of Non-Crystalline Solids, Vol. 351, No. 49-51, pp. 3716-3724, 0022-3093.

$\mathrm{Kim}, \mathrm{Y}$., et al., (2006), Anomalous ionic conductivity increase in $\mathrm{Li}_{2} \mathrm{~S}+\mathrm{GeS}_{2}+\mathrm{GeO}_{2}$ glasses: Journal of Physical Chemistry B, Vol. 110, No. 33, pp. 16318-16325, 1089-5647.

Komaba, S., et al., (2000), Preparation of Li-Mn-O thin films by r.f.-sputtering method and its application to rechargeable batteries: Journal of Applied Electrochemistry, Vol. 30, No. 10, pp. 1179-1182, 0021-891X. 
Komiya, R., et al., (2001), Solid state lithium secondary batteries using an amorphous solid electrolyte in the system $(100-x)\left(0.6 \mathrm{Li}_{2} \mathrm{~S}+0.4 \mathrm{SiS}_{2}\right)+\mathrm{xLi}_{4} \mathrm{SiO}_{4}$ obtained by mechanochemical synthesis: Solid State Ionics, Vol. 140, No. 1-2, pp. 83-87, 01672738.

Kondo, S., et al., (1992), New lithium ion conductors based on $\mathrm{Li}_{2} \mathrm{~S}-\mathrm{SiS}_{2}$ system: Solid State Ionics, Vol. 53-56, No. Part 2, pp. 1183-1186, 0167-2738.

Kong, Y. C., et al., (2001), Ultraviolet-emitting ZnO nanowires synthesized by a physical vapor deposition approach: Applied Physics Letters, Vol. 78, No. 4, pp. 407-409, 00036951.

Kubota, Y., et al., (2008), Electronic structure of LiSi: Journal of Alloys and Compounds, Vol. 458, No. 1-2, pp. 151-157, 0925-8388.

Kumta, P. N., et al., (1998), Synthesis of $\mathrm{LiCoO}_{2}$ powders for lithium-ion batteries from precursors derived by rotary evaporation: Journal of Power Sources, Vol. 72, No. 1, pp. 91-98, 0378-7753.

Lapp, T., et al., (1983), Ionic conductivity of pure and doped $\mathrm{Li}_{3} \mathrm{~N}$ : Solid State Ionics, Vol. 11, No. 2, pp. 97-103, 0167-2738.

Larson, R. W., and D. E. Day, (1986), Preparation and characterization of lithium phosphorus oxynitride glass: Journal of Non-Crystalline Solids, Vol. 88, No. 1, pp. 97113, 0022-3093.

Lee, C. H., et al., (2002), Characterizations of a new lithium ion conducting $\mathrm{Li}_{2} \mathrm{O}-\mathrm{SeO}_{2}-\mathrm{B}_{2} \mathrm{O}_{3}$ glass electrolyte: Solid State Ionics, Vol. 149, No. 1-2, pp. 59-65, 0167-2738.

Lee, S.-J., et al., (2001), Stress effect on cycle properties of the silicon thin-film anode: Journal of Power Sources, Vol. 97-98, pp. 191-193, 0378-7753.

Lee, S., et al., (2007), Modification of network structure induced by glass former composition and its correlation to the conductivity in lithium borophosphate glass for solid state electrolyte: Solid State Ionics, Vol. 178, No. 5-6, pp. 375-379, 0167-2738.

Lee, S. W., et al., (2004), Electrochemical characteristics of $\mathrm{Al}_{2} \mathrm{O}_{3}$-coated lithium manganese spinel as a cathode material for a lithium secondary battery: Journal of Power Sources, Vol. 126, No. 1-2, pp. 150-155, 0378-7753.

Li, W., et al., (1992), Crystal-Structure of Lixni2-Xo2 and a Lattice-Gas Model for the OrderDisorder Transition: Physical Review B, Vol. 46, No. 6, pp. 3236-3246, 0163-1829.

Li, X. X., et al., (2007), Electrochemical lithium intercalation/deintercalation of singlecrystalline $\mathrm{V}_{2} \mathrm{O}_{5}$ nanowires: Journal of the Electrochemical Society, Vol. 154, No. 1, pp. A39-A42, 0013-4651.

Liu, R. S., and C. H. Shen, (2003), Structural and electrochemical study of cobalt doped $\mathrm{LiMn}_{2} \mathrm{O}_{4}$ spinels: Solid State Ionics, Vol. 157, No. 1-4, pp. 95-100, 0167-2738.

Machida, N., et al., (2002), All-solid-state lithium battery with $\mathrm{LiCo}_{0.3} \mathrm{Ni}_{0.7} \mathrm{O}_{2}$ fine powder as cathode materials with an amorphous sulfide electrolyte: Journal of the Electrochemical Society, Vol. 149, No. 6, pp. A688-A693, 0013-4651.

Machida, N., et al., (2004), A new amorphous lithium-ion conductor in the system $\mathrm{Li}_{2} \mathrm{~S}-\mathrm{P}_{2} \mathrm{~S}_{3}$ : Chemistry Letters, Vol. 33, No. 1, pp. 30-31, 0366-7022.

Malta, M., and R. M. Torresi, (2005), Electrochemical and kinetic studies of lithium intercalation in composite nanofibers of vanadium oxide/polyaniline: Electrochimica Acta, Vol. 50, No. 25-26, pp. 5009-5014, 0013-4686.

Marchand, R., et al., (1988), Characterization of Nitrogen Containing Phosphate-Glasses by X-Ray Photoelectron-Spectroscopy: Journal of Non-Crystalline Solids, Vol. 103, No. 1, pp. 35-44, 0022-3093. 
Martin, S. W., (1991), Ionic-conduction in phosphate-glasses: Journal of the American Ceramic Society, Vol. 74, No. 8, pp. 1767-1784, 0002-7820.

Martin, S. W., and C. A. Angell, (1984), Conductivity Maximum in Sodium Aluminoborate Glass: Journal of the American Ceramic Society, Vol. 67, No. 7, pp. C148-C150, 00027820.

Mercier, R., et al., (1981a), Superionic conduction in $\mathrm{Li}_{2} \mathrm{~S}_{-} \mathrm{P}_{2} \mathrm{~S}_{5}-\mathrm{LiI}$ - glasses: Solid State Ionics, Vol. 5, pp. 663-666, 0167-2738.

Mercier, R., et al., (1981b), Superionic Conduction in $\mathrm{Li}_{2} \mathrm{~S}_{-} \mathrm{P}_{2} \mathrm{~S}_{5}-\mathrm{LiI}-\mathrm{Glasses}$ : Solid State Ionics, Vol. 5, No. Oct, pp. 663-666, 0167-2738.

Minami, K., et al., (2011), Electrical and electrochemical properties of glass-ceramic electrolytes in the systems $\mathrm{Li}_{2} \mathrm{~S}-\mathrm{P}_{2} \mathrm{~S}_{5}-\mathrm{P}_{2} \mathrm{~S}_{3}$ and $\mathrm{Li}_{2} \mathrm{~S}_{-}-\mathrm{P}_{2} \mathrm{~S}_{5}-\mathrm{P}_{2} \mathrm{O}_{5}$ : Solid State Ionics, Vol. 192, No. 1, pp. 122-125, 0167-2738.

Minami, K., et al., (2008), Structure and properties of the $70 \mathrm{Li}_{2} \mathrm{~S}+(30-\mathrm{x}) \mathrm{P}_{2} \mathrm{~S}_{5}+x \mathrm{P}_{2} \mathrm{O}_{5}$ oxysulfide glasses and glass-ceramics: Journal of Non-Crystalline Solids, Vol. 354, No. 2-9, pp. 370-373, 0022-3093.

Minami, T., et al., (2006), Recent progress of glass and glass-ceramics as solid electrolytes for lithium secondary batteries: Solid State Ionics, Vol. 177, No. 26-32, pp. 2715-2720, 0167-2738.

Mitkova, M., et al., (2004), Thermal and photodiffusion of Ag in S-rich Ge-S amorphous films: Thin Solid Films, Vol. 449, No. 1-2, pp. 248-253, 0040-6090.

Miyauchi, K., et al., (1983), Lithium Ion Conductive Thin-Films and Their ElectricalProperties: Denki Kagaku, Vol. 51, No. 1, pp. 211-212, 0366-9297.

Mizuno, F., et al., (2005), New, highly ion-conductive crystals precipitated from $\mathrm{Li}_{2} \mathrm{~S}-\mathrm{P}_{2} \mathrm{~S}_{5}$ glasses: Advanced Materials, Vol. 17, No. 7, pp. 918-+, 0935-9648.

Mizushima, K., et al., (1980), $\mathrm{Li}_{\mathrm{x}} \mathrm{CoO}_{2}$ "(Oless-Thanxless-Than-or-Equal-To1) - a New Cathode Material for Batteries of High-Energy Density: Materials Research Bulletin, Vol. 15, No. 6, pp. 783-789, 0025-5408.

Mount, E., (2003), Principles of Chemical Vapor Deposition (Book): Sci-Tech News, Vol. 57, No. 4, pp. 80, 00368059.

Murayama, M., et al., (2002), Structure of the thio-LISICON, $\mathrm{Li}_{4} \mathrm{GeS}_{4}$ : Solid State Ionics, Vol. 154-155, pp. 789-794, 0167-2738.

Murayama, M., et al., (2004), Material design of new lithium ionic conductor, thio-LISICON, in the $\mathrm{Li}_{2} \mathrm{~S}_{-} \mathrm{P}_{2} \mathrm{~S}_{5}$ system: Solid State Ionics, Vol. 170, No. 3-4, pp. 173-180, 0167-2738.

Myung, S.-T., et al., (2000), Capacity fading of $\mathrm{LiMn}_{2} \mathrm{O}_{4}$ electrode synthesized by the emulsion drying method: Journal of Power Sources, Vol. 90, No. 1, pp. 103-108, 03787753.

Nakayama, M., et al., (2003), Grain size control of $\mathrm{LiMn}_{2} \mathrm{O}_{4}$ cathode material using microwave synthesis method: Solid State Ionics, Vol. 164, No. 1-2, pp. 35-42, 01672738.

Nalwa, H. S., (2002), Handbook of thin film materials: San Diego, Academic Press, 0125129084 (set acid-free paper)

Narayan, J., et al., (1992), Epitaxial growth of Tin Films on (100) silicon substrates by laser physical vapor deposition: Applied Physics Letters, Vol. 61, No. 11, pp. 1290-1292, 0003-6951.

Neudecker, B. J., et al., (2000), "Lithium-Free" Thin-Film Battery with In Situ Plated Li Anode: Journal of The Electrochemical Society, Vol. 147, No. 2, pp. 517-523, 
Nishida, Y., et al., (1997), Synthesis and properties of gallium-doped $\mathrm{LiNiO}_{2}$ as the cathode material for lithium secondary batteries: Journal of Power Sources, Vol. 68, No. 2, pp. 561-564, 0378-7753.

Nogami, M., and Y. Moriya, (1982), Glass formation of the $\mathrm{SiO}_{2}-\mathrm{B}_{2} \mathrm{O}_{3}$ system by the gel process from metal alkoxides: Journal of Non-Crystalline Solids, Vol. 48, No. 2-3, pp. 359-366, 0022-3093.

Ohtomo, T., et al., (2005), Electrical and electrochemical properties of $\mathrm{Li}_{2} \mathrm{~S}-\mathrm{P}_{2} \mathrm{~S}_{5}-\mathrm{P}_{2} \mathrm{O}_{5}$ glassceramic electrolytes: Journal of Power Sources, Vol. 146, No. 1-2, pp. 715-718, 03787753.

Ohtsuka, H., et al., (1990), Solid-State Battery with $\mathrm{Li}_{2} \mathrm{O}-\mathrm{V}_{2} \mathrm{O}_{5}-\mathrm{SiO}_{2}$ Solid Electrolyte ThinFilm: Solid State Ionics, Vol. 40-1, pp. 964-966, 0167-2738.

Ohtsuka, H., and J. Yamaki, (1989), Electrical Characteristics of $\mathrm{Li}_{2} \mathrm{O}-\mathrm{V}_{2} \mathrm{O}_{5}-\mathrm{SiO}_{2}$ Thin-Films: Solid State Ionics, Vol. 35, No. 3-4, pp. 201-206, 0167-2738.

Ohzuku, T., et al., (1991), Electrochemistry of Manganese-Dioxide in Lithium Nonaqueous Cells .4. Jahn-Teller Deformation of $\mathrm{MnO}_{6}$-Octahedron in $\mathrm{Li}_{x} \mathrm{MnO}_{2}$ : Journal of the Electrochemical Society, Vol. 138, No. 9, pp. 2556-2560, 0013-4651.

Padhi, A. K., et al., (1997), Phospho-olivines as positive-electrode materials for rechargeable lithium batteries: Journal of the Electrochemical Society, Vol. 144, No. 4, pp. 1188-1194, 0013-4651.

Pang, S. P., et al., (2005), Synthesis of polyaniline-vanadium oxide nanocomposite nanosheets: Macromolecular Rapid Communications, Vol. 26, No. 15, pp. 1262-1265, 1022-1336.

Park, H. Y., et al., (2007), $\mathrm{LiCoO}_{2}$ thin tilm cathode fabrication by rapid thermal annealing for micro power sources: Electrochimica Acta, Vol. 52, No. 5, pp. 2062-2067, 00134686.

Park, K. S., et al., (2005), The effects of sulfur doping on the performance of O.3Li$0.7\left[\mathrm{Li}_{1 / 12} \mathrm{Ni}_{1 / 12} \mathrm{Mn}_{5 / 6}\right] \mathrm{O}_{2}$ powder: Korean Journal of Chemical Engineering, Vol. 22, No. 4, pp. 560-565, 0256-1115.

Park, S. H., and Y. K. Sun, (2003), Synthesis and electrochemical properties of layered $\mathrm{Li}\left[\mathrm{Li}_{0.15} \mathrm{Ni}\left(0.275_{x / 2}\right) \mathrm{Al}_{x} \mathrm{Mn}\left(0.575_{x / 2}\right)\right]_{2}$ materials: Journal of Power Sources, Vol. 119, pp. 161-165, 0378-7753.

Park, Y. S., et al., (1999), All-solid-state lithium thin-film rechargeable battery with lithium manganese oxide: Electrochemical and Solid State Letters, Vol. 2, No. 2, pp. 58-59, 1099-0062.

Patel, H. K., and S. W. Martin, (1992), Fast ionic conduction in $\mathrm{Na}_{2} \mathrm{~S}+\mathrm{B}_{2} \mathrm{~S}_{3}$ glasses: Compositional contributions to nonexponentiality in conductivity relaxation in the extreme low-alkali-metal limit: Physical Review B, Vol. 45, No. 18, pp. 10292,

Patil, A., et al., (2008), Issue and challenges facing rechargeable thin film lithium batteries: Materials Research Bulletin, Vol. 43, No. 8-9, pp. 1913-1942, 0025-5408.

Peled, E., et al., (1996), Improved Graphite Anode for Lithium-Ion Batteries Chemically: Journal of the Electrochemical Society, Vol. 143, No. 1, pp. L4-L7,

Peng, Z. S., et al., (1998), Synthesis by sol-gel process and characterization of $\mathrm{LiCoO}_{2}$ cathode materials: Journal of Power Sources, Vol. 72, No. 2, pp. 215-220, 0378-7753.

Pouillerie, C., et al., (2000), Synthesis and characterization of new $\mathrm{LiNi}_{1-\mathrm{y}} \mathrm{Mg}_{\mathrm{y}} \mathrm{O}_{2}$ positive electrode materials for lithium-ion batteries: Journal of the Electrochemical Society, Vol. 147, No. 6, pp. 2061-2069, 0013-4651. 
Pradel, A., et al., (1985), Effect of rapid quenching on electrical properties of lithium conductive glasses: Solid State Ionics, Vol. 17, No. 2, pp. 147-154, 0167-2738.

Prosini, P. P., et al., (2001), Improved electrochemical performance of a $\mathrm{LiFePO}_{4}$-based composite cathode: Electrochimica Acta, Vol. 46, No. 23, pp. 3517-3523, 0013-4686.

Rabenau, A., (1982), Lithium Nitride and Related Materials - Case-Study of the Use of Modern Solid-State Research Techniques: Solid State Ionics, Vol. 6, No. 4, pp. 277293, 0167-2738.

Rajendran, S., and T. Uma, (2000), Conductivity studies on PVC/PMMA polymer blend electrolyte: Materials Letters, Vol. 44, No. 3-4, pp. 242-247, 0167-577X.

Reimers, J. N., et al., (1993), Structure and Electrochemistry of $\mathrm{Li}_{\mathrm{x}} \mathrm{Fe}_{\mathrm{y}} \mathrm{Ni}_{1-\mathrm{y}} \mathrm{O}_{2}$ : Solid State Ionics, Vol. 61, No. 4, pp. 335-344, 0167-2738.

Sakamoto, R., et al., (1999), Preparation of fast lithium ion conducting glasses in the system $\mathrm{Li}_{2} \mathrm{~S}-\mathrm{SiS}_{2}-\mathrm{Li}_{3} \mathrm{~N}$ : Journal of Physical Chemistry B, Vol. 103, No. 20, pp. 4029-4031, 10895647.

Sakka, S., (1986), Oxynitride Glasses: Annual Review of Materials Science, Vol. 16, pp. 29-46, 0084-6600.

Saunier, J., et al., (2004), Plasticized microporous poly(vinylidene fluoride) separators for lithium-ion batteries. II. Poly(vinylidene fluoride) dense membrane swelling behavior in a liquid electrolyte - Characterization of the swelling kinetics: Journal of Polymer Science Part B-Polymer Physics, Vol. 42, No. 3, pp. 544-552, 0887-6266.

Schalkwijk, W. A. v., and B. Scrosati, (2002), Advances in lithium-ion batteries: New York, NY, Kluwer Academic/Plenum Publishers, x, 513 p. pp., 0306473569.

Scholz, F., and B. Meyer, (1994), ELECTROCHEMICAL SOLID-STATE ANALYSIS - STATEOF-THE-ART: Chemical Society Reviews, Vol. 23, No. 5, pp. 341-347, 0306-0012.

Seo, I., and S. W. Martin, (2011a), Fast lithium ion conducting solid state thin-film electrolytes based on lithium thio-germanate materials: Acta Materialia, Vol. 59, No. 4, pp. 1839-1846, 1359-6454.

Seo, I., and S. W. Martin, (2011b), Preparation and Characterization of Fast Ion Conducting Lithium Thio-Germanate Thin Films Grown by RF Magnetron Sputtering: Journal of the Electrochemical Society, Vol. 158, No. 5, pp. A465-A470, 0013-4651.

Seo, I., and S. W. Martin, (2011c), Structural Properties of Lithium Thio-Germanate Thin Film Electrolytes Grown by Radio Frequency Sputtering: Inorganic Chemistry, Vol. 50, No. 6, pp. 2143-2150, 0020-1669.

Sharma, R. A., and R. N. Seefurth, (1976), Thermodynamic Properties of the Lithium-Silicon System: Journal of the Electrochemical Society, Vol. 123, No. 12, pp. 1763-1768,

Shi, S. Q., et al., (2003), Enhancement of electronic conductivity of $\mathrm{LiFePO}_{4}$ by $\mathrm{Cr}$ doping and its identification by first-principles calculations: Physical Review B, Vol. 68, No. 19, pp. -, 1098-0121.

Shokoohi, F. K., et al., (1991), Fabrication of Thin-Film $\mathrm{LiMn}_{2} \mathrm{O}_{4}$ Cathodes for Rechargeable Microbatteries: Applied Physics Letters, Vol. 59, No. 10, pp. 1260-1262, 0003-6951.

Sigala, C., et al., (1995), Positive Electrode Materials with High Operating Voltage for Lithium Batteries - $\mathrm{LiCr}_{\mathrm{y}} \mathrm{Mn}_{2-\mathrm{y}} \mathrm{O}_{4}$ (0-Less-Than-or-Equal-to-Y-Less-Than-or-Equalto-1): Solid State Ionics, Vol. 81, No. 3-4, pp. 167-170, 0167-2738.

Song, J. Y., et al., (1999), Review of gel-type polymer electrolytes for lithium-ion batteries: Journal of Power Sources, Vol. 77, No. 2, pp. 183-197, 0378-7753. 
Souquet, J. L., and M. Duclot, (2002), Thin film lithium batteries: Solid State Ionics, Vol. 148, No. 3-4, pp. 375-379, 0167-2738.

Tabata, H., et al., (1994), Formation of artificial $\mathrm{BaTiO}_{3}-\mathrm{SrTiO}_{3}$ superlattices using pulsed laser deposition and their dielectric properties: Applied Physics Letters, Vol. 65, No. 15, pp. 1970-1972, 0003-6951.

Takada, K., et al., (1995), Electrochemical behavior of $\mathrm{Li}_{x} \mathrm{MO}_{2}(\mathrm{M}=\mathrm{Co}, \mathrm{Ni})$ in all solid state cells using a glass electrolyte: Solid State Ionics, Vol. 79, pp. 284-287, 0167-2738.

Takada, K., et al., (1996), Solid state lithium battery with oxysulfide glass: Solid State Ionics, Vol. 86-8, pp. 877-882, 0167-2738.

Tarascon, J. M., and M. Armand, (2001), Issues and challenges facing rechargeable lithium batteries: Nature, Vol. 414, No. 6861, pp. 359-367, 0028-0836.

Unuma, H., and S. Sakka, (1987), Electrical-Conductivity in Na-Si-O-N Oxynitride Glasses: Journal of Materials Science Letters, Vol. 6, No. 9, pp. 996-998, 0261-8028.

Volynsky, A. B., et al., (2001), Low-temperature transformations of sodium sulfate and sodium selenite in the presence of pre-reduced palladium modifier in graphite furnaces for electrothermal atomic absorption spectrometry: Spectrochimica Acta Part B-Atomic Spectroscopy, Vol. 56, No. 8, pp. 1387-1396, 0584-8547.

Wada, H., et al., (1983), Preparation and ionic conductivity of new $\mathrm{B}_{2} \mathrm{~S}_{3}-\mathrm{Li}_{2} \mathrm{~S}-\mathrm{LiI}$ glasses: Materials Research Bulletin, Vol. 18, No. 2, pp. 189-193, 0025-5408.

Wang, B., et al., (1995a), Ionic conductivities of lithium phosphorus oxynitride glasses, polycrystals and thin films: Solid State Ionics Iv, Vol. 369, pp. 445-456, 0272-9172.

Wang, B., et al., (1995b), Synthesis, Crystal-Structure, and Ionic-Conductivity of a Polycrystalline Lithium Phosphorus Oxynitride with the Gamma-Li3po4 Structure: Journal of Solid State Chemistry, Vol. 115, No. 2, pp. 313-323, 0022-4596.

Wang, B., et al., (1995c), Ionic Conductivities and Structure of Lithium Phosphorus Oxynitride Glasses: Journal of Non-Crystalline Solids, Vol. 183, No. 3, pp. 297-306, 0022-3093.

Wang, H. F., et al., (1999), TEM study of electrochemical cycling-induced damage and disorder in $\mathrm{LiCoO} 2$ cathodes for rechargeable lithium batteries: Journal of the Electrochemical Society, Vol. 146, No. 2, pp. 473-480, 0013-4651.

Wang, Y., and G. Z. Cao, (2008), Developments in nanostructured cathode materials for high-performance lithium-ion batteries: Advanced Materials, Vol. 20, No. 12, pp. 2251-2269, 0935-9648.

Wang, Z., et al., (2002), Structural and electrochemical characterizations of surface-modified LiCoO2 cathode materials for Li-ion batteries: Solid State Ionics, Vol. 148, No. 3-4, pp. 335-342, 0167-2738.

West, W. C., et al., (2004), Chemical stability enhancement of lithium conducting solid electrolyte plates using sputtered LiPON thin films: Journal of Power Sources, Vol. 126, No. 1-2, pp. 134-138, 0378-7753.

Whittingham, M. S., (1976), Role of Ternary Phases in Cathode Reactions: Journal of the Electrochemical Society, Vol. 123, No. 3, pp. 315-320, 0013-4651.

Whittingham, M. S., (2004), Lithium batteries and cathode materials: Chemical Reviews, Vol. 104, No. 10, pp. 4271-4301, 0009-2665.

Willmott, P. R., and J. R. Huber, (2000), Pulsed laser vaporization and deposition: Reviews of Modern Physics, Vol. 72, No. 1, pp. 315, 
Wu, H. Z., et al., (2000), Low-temperature epitaxy of $\mathrm{ZnO}$ films on $\mathrm{Si}(001)$ and silica by reactive e-beam evaporation: Journal of Crystal Growth, Vol. 217, No. 1-2, pp. 131$137,0022-0248$.

Wu, Y. P., et al., (2003), Carbon anode materials for lithium ion batteries: Journal of Power Sources, Vol. 114, No. 2, pp. 228-236, 0378-7753.

Xia, H., et al., (2009), Thin film Li electrolytes for all-solid-state micro-batteries: International Journal of Surface Science and Engineering, Vol. 3, No. 1-2, pp. 23-43, 1749-785X.

Xu, K., et al., (2002), Lithium Bis(oxalato)borate Stabilizes Graphite Anode in Propylene Carbonate: Electrochemical and Solid-State Letters, Vol. 5, No. 11, pp. A259-A262,

Yamada, A., et al., (2001), Optimized $\mathrm{LiFePO}_{4}$ for lithium battery cathodes: Journal of the Electrochemical Society, Vol. 148, No. 3, pp. A224-A229, 0013-4651.

Yamaki, J., et al., (1996), Rechargeable lithium thin film cells with inorganic electrolytes: Solid State Ionics, Vol. 86-8, pp. 1279-1284, 0167-2738.

Yamashita, M., et al., (1999), Studies on magnetron sputtering assisted by inductively coupled RF plasma for enhanced metal ionization: Japanese Journal of Applied Physics Part 1-Regular Papers Short Notes \& Review Papers, Vol. 38, No. 7B, pp. 4291-4295, 0021-4922.

Yamashita, M., and H. Yamanaka, (2003), Formation and ionic conductivity of $\mathrm{Li}_{2} \mathrm{~S}-\mathrm{GeS}_{2}-$ $\mathrm{Ga}_{2} \mathrm{~S}_{3}$ glasses and thin films: Solid State Ionics, Vol. 158, No. 1-2, pp. 151-156, 01672738.

Yamashita, M., et al., (1996a), Thin-film preparation of the $\mathrm{Li}_{2} \mathrm{~S}-\mathrm{GeS}_{2}-\mathrm{Ga}_{2} \mathrm{~S}_{3}$ glass system by sputtering: Solid State Ionics, Vol. 89, No. 3-4, pp. 299-304, 0167-2738.

Yamashita, M., et al., (1996b), Thin-film preparation of the $\mathrm{Li}_{2} \mathrm{~S}-\mathrm{GeS}_{2}-\mathrm{Ga}_{2} \mathrm{~S}_{3}$ glass system by sputtering: Solid State Ionics, Vol. 89, No. 3-4, pp. 299-304, 0167-2738.

Yonco, R. M., et al., (1975), Solubility of Nitrogen in Liquid Lithium and ThermalDecomposition of Solid Li3n: Journal of Nuclear Materials, Vol. 57, No. 3, pp. 317-324, 0022-3115.

Yonezawa, S., et al., (1998), Effect of $\mathrm{LiF}$ addition at preparation of $\mathrm{LiCoO}_{2}$ on its properties as an active material of lithium secondary battery: Journal of Fluorine Chemistry, Vol. 87, No. 2, pp. 141-143, 0022-1139.

Yoshitake, T., et al., (2001), Microstructure of $\beta$-FeSi 2 thin films prepared by pulsed laser deposition: Thin Solid Films, Vol. 381, No. 2, pp. 236-243, 0040-6090.

$\mathrm{Yu}, \mathrm{M} . \mathrm{X}$., et al., (2001), Investigation on structure and conductivity of microporous pan electrolyte: Acta Polymerica Sinica, No. 5, pp. 665-669, 1000-3304.

Yu, X., et al., (1997), A Stable Thin-Film Lithium Electrolyte: Lithium Phosphorus Oxynitride: Journal of The Electrochemical Society, Vol. 144, No. 2, pp. 524-532,

Zhang, B., et al., (2004), Study on the structure and dielectric properties of $\mathrm{BaO}-\mathrm{SiO}_{2}-\mathrm{B}_{2} \mathrm{O}_{3}$ glass-doped (Ba,Sr) $\mathrm{TiO}_{3}$ ceramics: Ceramics International, Vol. 30, No. 7, pp. 1767$1771,0272-8842$.

Zhang, Z., and J. H. Kennedy, (1990), Synthesis and characterization of the $\mathrm{B}_{2} \mathrm{~S}_{3}-\mathrm{Li}_{2} \mathrm{~S}$, the $\mathrm{P}_{2} \mathrm{~S}_{5}-\mathrm{Li}_{2} \mathrm{~S}$ and the $\mathrm{B}_{2} \mathrm{~S}_{3}-\mathrm{P}_{2} \mathrm{~S}_{5}-\mathrm{Li}_{2} \mathrm{~S}$ glass systems: Solid State Ionics, Vol. 38, No. 3-4, pp. 217-224, 0167-2738.

Zhecheva, E., and R. Stoyanova, (1993), Stabilization of the Layered Crystal-Structure of $\mathrm{LiNiO}_{2}$ by Co-Substitution: Solid State Ionics, Vol. 66, No. 1-2, pp. 143-149, 01672738 . 
Zhou, Z. H., et al., (1999), Structure of $\mathrm{Na}_{2} \mathrm{~S}-\mathrm{GeS}_{2}$ sulphide glasses - comparison with $\mathrm{Na}_{2} \mathrm{O}-$ $\mathrm{GeO}_{2}$ oxide glasses: Physics and Chemistry of Glasses, Vol. 40, No. 3, pp. 146-152, 0031-9090. 


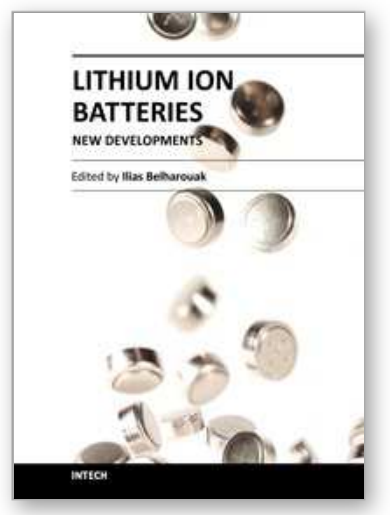

\author{
Lithium Ion Batteries - New Developments \\ Edited by Dr. llias Belharouak
}

ISBN 978-953-51-0077-5

Hard cover, 226 pages

Publisher InTech

Published online 24, February, 2012

Published in print edition February, 2012

The eight chapters in this book cover topics on advanced anode and cathode materials, materials design, materials screening, electrode architectures, diagnostics and materials characterization, and electrode/electrolyte interface characterization for lithium batteries. All these topics were carefully chosen to reflect the most recent advances in the science and technology of rechargeable Li-ion batteries, to provide wide readership with a platform of subjects that will help in the understanding of current technologies, and to shed light on areas of deficiency and to energize prospects for future advances.

\title{
How to reference
}

In order to correctly reference this scholarly work, feel free to copy and paste the following:

Inseok Seo and Steve W. Martin (2012). New Developments in Solid Electrolytes for Thin-Film Lithium Batteries, Lithium Ion Batteries - New Developments, Dr. llias Belharouak (Ed.), ISBN: 978-953-51-0077-5, InTech, Available from: http://www.intechopen.com/books/lithium-ion-batteries-new-developments/newdevelopments-in-solid-electrolytes-for-thin-film-lithium-batteries

\section{INTECH}

open science | open minds

\section{InTech Europe}

University Campus STeP Ri

Slavka Krautzeka 83/A

51000 Rijeka, Croatia

Phone: +385 (51) 770447

Fax: +385 (51) 686166

www.intechopen.com

\section{InTech China}

Unit 405, Office Block, Hotel Equatorial Shanghai

No.65, Yan An Road (West), Shanghai, 200040, China

中国上海市延安西路65号上海国际贵都大饭店办公楼 405 单元

Phone: +86-21-62489820

Fax: +86-21-62489821 
(C) 2012 The Author(s). Licensee IntechOpen. This is an open access article distributed under the terms of the Creative Commons Attribution 3.0 License, which permits unrestricted use, distribution, and reproduction in any medium, provided the original work is properly cited. 